\title{
CHEMICAL METHODS FOR ROUTINE BIOASSAY
}

Edited by

John B Hursh

November 1958

University of Rochester

Rochester, New York

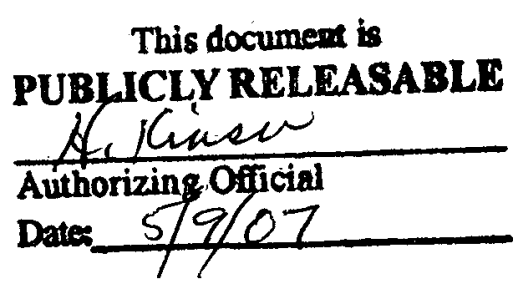

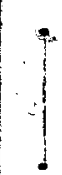

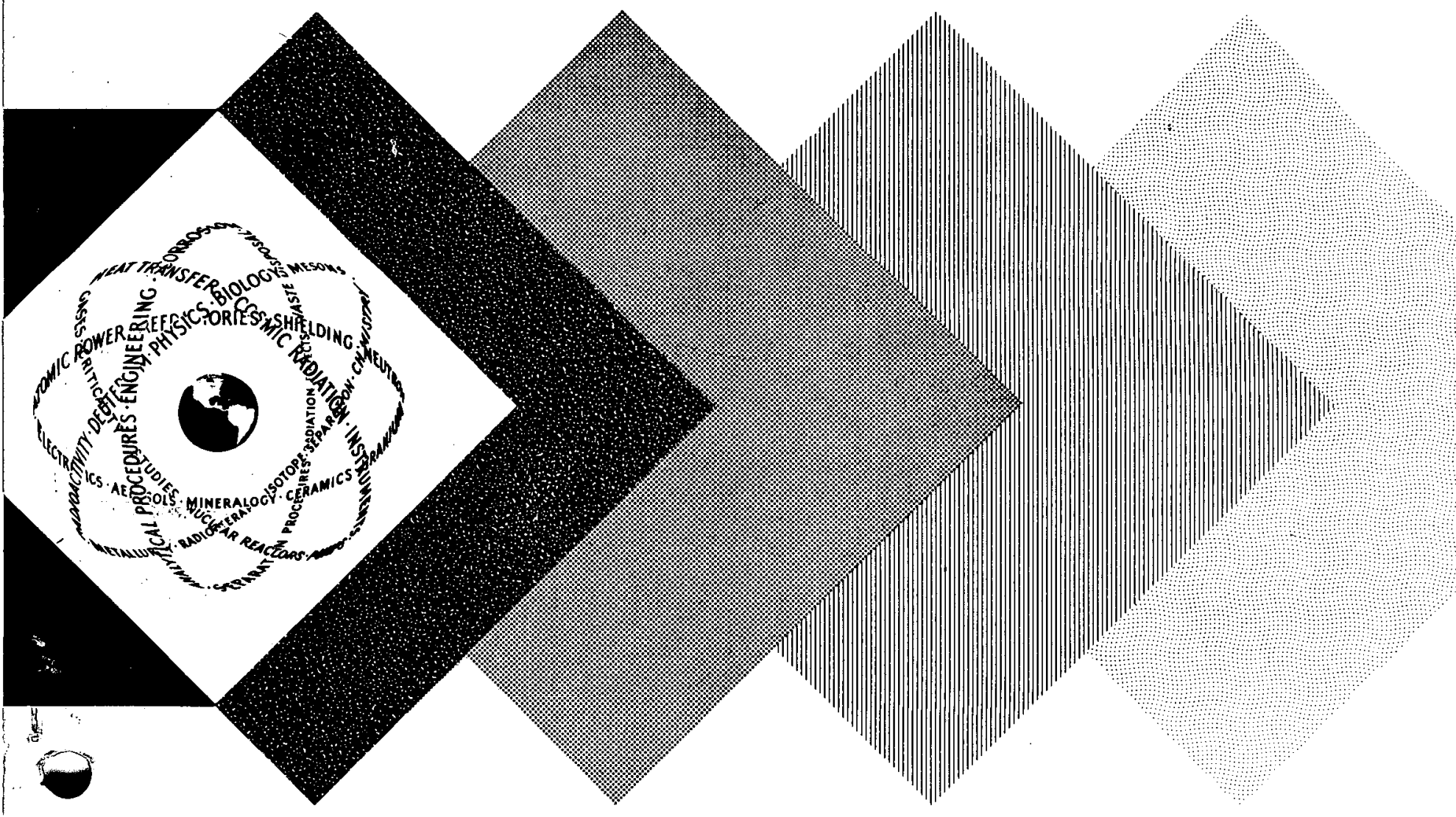

UNITED STATES ATOMIC ENERGY COMMISSION

Technical Information Service 


\section{DISCLAIMER}

This report was prepared as an account of work sponsored by an agency of the United States Government. Neither the United States Government nor any agency Thereof, nor any of their employees, makes any warranty, express or implied, or assumes any legal liability or responsibility for the accuracy, completeness, or usefulness of any information, apparatus, product, or process disclosed, or represents that its use would not infringe privately owned rights. Reference herein to any specific commercial product, process, or service by trade name, trademark, manufacturer, or otherwise does not necessarily constitute or imply its endorsement, recommendation, or favoring by the United States Government or any agency thereof. The views and opinions of authors expressed herein do not necessarily state or reflect those of the United States Government or any agency thereof. 


\section{DISCLAIMER}

Portions of this document may be illegible in electronic image products. Images are produced from the best available original document. 


\section{LEGAL NOTICE}

This report was prepared as an account of Government sponsored work. Neither the United States, nor the Commission, nor any person acting on behalf of the Commission:

A. Makes any warranty or representation. expressed or implied, with respect to the accuracy, completeness. or usefulness of the information contained in this report, or that the use of any information, apparatus, method, or process disclosed in this report may not infringe privately owned rights; or

B. Assumes any liabilities with respect to the use of, or for damages resulting from the use of any information, apparatus, method, or process disclosed in this report.

As used in the above, "person acting on behalf of the Commission" includes any employee or contractor of the Commission. or employee of such contractor, to the extent that such employee or contractor of the Commission. or employee of such contractor prepares, disseminates, or provides access to, any information pursuant to his employment or contract with the Commission. or his employment with such contractor.

This report has been reproduced directly from the best available copy.

Printed in USA. Price \$1.00. Available from the Office of Technical Services, Department of Commerce, Washington 25, D. C.

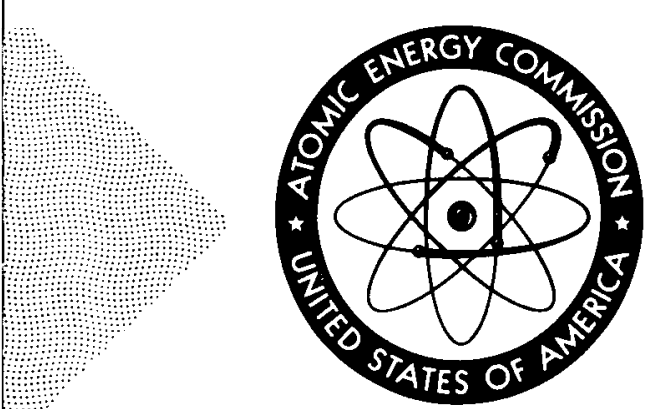


TABLE OF CONTENTS

Page

PREFACE ............................. . . i . . . . . . . . FOREWORD .................................... . iv

Bioassay Procedures for Plutonium, reviewed by Morris F. Killigan . 1

Bioassay Procedures for Polonium, reviewed by Robert G. Thomas - e 13

Bioassay Procedures for Radium, reviewed by John B. Hursh • . . • 19

Bioassay Procedures for Thorium, reviewed by George A. Welford • • 30

Bioassay Procedures for Tritium, reviewed by Julian M. Nielson . • 38

Bioassay Procedures for Uranium, reviewed by Mont G. Mason - - - 59

Bioassay Procedures for Strontium, reviewed by John H. Harley • e • 74 

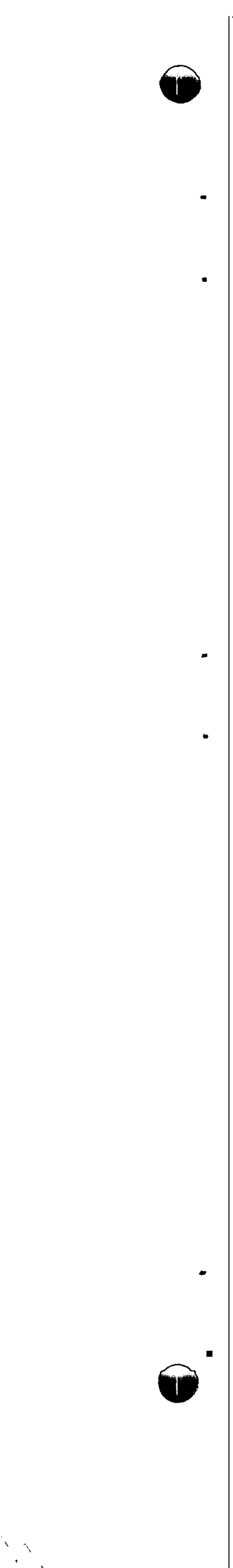
A the request of the Division of Biology and Medicine, A.E.C., members of the Analytical Chemistry and BioAssay Group have reviewed methods in routine use for bioassay of materials of interest, and have selected methods for plutonium, polonium, radium, thorium, tritium, uranium, and strontium which in their opinion were useful for this purpose, The description of procedure has in sone cases been recast into what was judged to be a more convenient form, with the original method or methods acknowledged in the references cited at the end of the method description. Any reference herein to limits for urine or body burden have not the force of recommendations? but serve merely to illustrate methods of data calculation or to relate the sensitivity of the method to the approxinate required sensitivity. It is realized that this compendium Kill require revision and amplification when alternative methods are developed. 
The preparation of this document was initiated by a request from the Division of Licensing and Regulation for a set of analytical procedures to be used in advising licensees on methods of monitoring internal radiation. There has been a growing need among licensees and others, particularly in small organizations without extensive health physics facilities, for help in establishing bioassay programs. To help fill this need, the Division of Biology and Medicine requested at the Third Annual Meeting of the Bioassay and Analytical Chemistry Group that an independent committee be organized to survey existing procedures and arrive at a set of representative chemical methods for analyzing biological materials. Certain isotopes of importance have been considered and have been included in this report to the extent that appropriate procedures were available. Procedures were collected from AEC Operations Offices and contractors, and were submitted to the reviewing committee that was formed in December, 1957, under the chairmanship of Dr. John B. Hursh. The members of the reviewing committee and the elements for which they prepared analytical procedures are as follows:

Monis F. Milligan

Ios Alamos Scientific Laboratory

University of California

Robert G. Thomas

University of Rochester

John B. Hursh (Chairman)

University of Rochester

George A. Welford

Health and Safety Laboratory

U. S. Atomic Energy Commission

Julian M. Nielson

Hanford Atomic Products Operation

General Electric Company
Plutonium

\section{Polonium}

Radium

Thorium

Tritium 


\section{Mont G• Mason and Richard H• Burr, Jr• Uranium Mallinckrodt Chemical Work6 \\ John H. Harley \\ Health and Safety Laboratory \\ Strontium \\ U. S. Atomic Energy Commission}

In addition to those listed above, the many individuals among AEC contractors and Operations Offices who cooperated so generously in providing detailed and up-to-date procedures deserve much appreciation.

Most of the procedures in the present study were collected by April, 1958, and a preliminary report by the committee was distributed by Dr. Hursh at the Fourth Annual Meeting of the Bioassay and Analytical Chemistry Group on November 3, 1958. The studies include procedures in use approximately up to that date. The present edition includes some procedures for radiostrontium, and other minor revisions, and was submitted by Dr. Hursh in December, 1958. Since the principle objective of the committee was accomplished upon the completion of this report, the committee dissolved itself in the expectation that any future updating of this material that might be required could be supported directly by the Atomic Energy Commission.

It should be noted that this report does not necessarily represent the recommendations or the policies of the Atomic Energy Commission or any other formal group. Neither is it claimed that the methods given here are the only acceptable methods of analysis for the elements concerned. Each reviewer selected procedures for the particular element that he studied on the basis of providing simple and reliable procedures to meet, the needs of the average user, and used his own judgment to decide the nature and variety of the methods to be included. 


\section{Foreword - 3}

The Division of Biology and Medicine believes that the procedures described in this report are satisfactory procedures and if carefully followed will provide reliable methods of analysis within the limits of precision specified. The Division of Biology and Medicine would recommend them for use within these limits.

Charles L. Dunham, M. D.

Director

Division of Biology and Medicine

U. S. Atomic Energy Commission 
Reviewer -- Morris F. Milligan

September 1958

I. Sample Collection. Since it is necessary to isolate and measure very small amounts of plutonium, the largest urine sample reasonably obtained is analyzed without aliquoting. In most instances, a 24-hour sample is used, although for routine work, the equivalent of a 24-hour sample may be conveniently substituted; this "equivalent" comprises a 11 urine passed for one half hour before retiring and for one half hour after arising for two consecutive days.

\section{Chemical Isolation Procedures.}

PROCEDURE $\mathbf{A}$.

This procedure has been widely used to isolate plutonium from urine samples in a form suitable for low-background electronic alpha counting'. Relying upon serial coprecipitation with bismuth phosphate and with lanthanum fluoride, it will also isolate actinium, thorium, neptunium, americium, and curium. Plutonium recoveries of 90 per cent are achieved, and the sensitivity is limited by the counter backgrounds. No unusual laboratory equipment is required.

Procedure

1. Transfer the urine sample to a 4-liter beaker, rinse the original container with $100 \mathrm{ml}$ conc. nitric acid, add rinsings to urine, and evaporate to dryness。

2. After the sample has cooled, add sufficient conc. nitric acid to cover the solids, and repeat the evaporation to dryness.

3. Repeat Step 2 until the sample is white when cool.

4. Drop $2 \mathrm{ml}$ conc, nitric acid over the solids. After brief standing, add $35 \mathrm{ml}$ water.

5. Transfer the solution (and suspended solids) to a $50 \mathrm{ml}$ conical centrifuge tube and centrifuge at $2000 \mathrm{rpm}$ for 5 minutes.

\section{Procedure No}

Glass beads or carborundum may be added to minimize bumping; commercial antifosm materials may be added to minimize foaming.

Oxides of nitrogen may cause the sample to appear brown when hot.

A small amount of solids remains in suspension. 


\section{$\underline{\text { Procedure }}$}

6. Decant the clear supernate into a $90 \mathrm{ml}$ round-end centrifuge tube.

7. Wash down the side of the $50 \mathrm{ml}$ tube with $1 \mathrm{ml}$ conc. nitric acid and then with 2 m water; slurry the insolubles, centrifuge, and decant the supernate into the main solution contained in the $90 \mathrm{~m} \mathrm{I}$ centrifuge tube.

8. Dilute the solution to $80 \mathrm{ml}$, add $2 \mathrm{ml}$ sulfurous acid, stir, and let stand 20 minutes at room temperature.

9. Place the tube in a constant temperature bath at $85-90^{\circ} \mathrm{C}$., stir constantly with a stirring motor; when the sol. reaches bath temperature, add dropwise $1 \mathrm{ml}$ bismuth nitrate solution.

10. Add $1 \mathrm{ml}$ of conc. phosphoric acid dropwise.

11. Allow the bismuth phosphate precipitate to digest with constant stirring at bath temperature for one hour.

12. Terminate stirring, remove the tubes from the bath, and allow the precipitate to settle. The tube may be centrifuged if necessary or desirable.

13. Suck off the supernate through a slender glass tube attached to a water aspirator.

14. Transfer the Precipitate and the 1 or $2 \mathrm{ml}$ of remaining liquid to a $15 \mathrm{~m} /$ conical centrifuge tube.

\section{$\underline{\text { Procedure Notes }}$}

In Steps 6 and 7, it is imperative that no solids be transferred.

Sulfurous acid, prepared by saturating distilled water with gaseous sulfur dioxide, assures reduction of hexavalent plutonium.

Bismuth nitrate solution is prepared by dissolving $232 \mathrm{gm}$ bismuth nitrate pentahydrate in $630 \mathrm{ml}$ conc. nitric acid, and diluting to 1 liter with water.

Digestion with stirring insures complete carrying of plutonium. 
Procedure

Wash down the $90 \mathrm{ml}$ tube

with $2 \mathrm{ml}$ water and add this to the $15 \mathrm{ml}$ tube.

15. Centrifuge the $15 \mathrm{ml}$ tube and discard the supernate. Wash the $90 \mathrm{~m} \mathrm{I}$ tube with 10 drops of conc hydrochloric acid followed by 10 drops of water; add this liquid to the precipitate in the $15 \mathrm{ml}$ tube. Repeat, using 10 drops of conc. hydrochloric acid followed by 10 drops of water. Stir until the bismuth phosphate dissolves.

16. Dilute the solution to $5 \mathrm{ml}$, add $0.5 \mathrm{~m} \mathrm{I}$ lanthanum nitrate solution and stir with a very thin platinum rod. Add $0.5 \mathrm{ml} 24$ per cent hydrofluoric acid and stir well.

17. Imediately centrifuge for 5 minutes, discard the supernate, wash the lanthanum fluoride precipitate with 5 m l water, centrifuge, and discard the washings.

18. Transfer the precipitate to a counting disk with the aid of $2 M$ nitric acid.

19. Evaporate the sample to dryness with infrared heat. Flame lightly to remove the last trace of organic matter.

20. Count on a low-background alpha counter.
Procedure Notes

Lanthanum nitrate solution may be prepared by dissolving 1.56 lanthanum nitrate hemhydrate in $63 \mathrm{ml}$ conc. nitric acid and diluting to one liter with water; 24 per cent hydrofluoric acid is prepared by $\mathrm{di-}$ luting the conc. 48 per cent acid with an equal volume of water.

Delay in centrifuging may result in reaction of the hydrofluoric acid with the glass.

Any platinum or stainless steel disk or planchet suitable to the counters may be used.

Overhead heating with infrared minimizes the possibility of spattering during evaporation. 
This procedure is used routinely where results of the greatest sensitivity are needed for continuous evaluation of possible lowlevel chronic exposures 2,3 . Plutonium is isolated by lenthanum fluoride coprecipitation, TTA (thenoyltrifluoroscetone) extraction, and preparation of the sample for counting by electrodeposition. The ins preparation may be counted electronically for rapid results, or by radioautography for results of greater sensitivity and precision.

\section{Procedure}

1. To the sample in a 1500 ml Erlenmeyer flask add sufficient conc nitric acid to produce a definite color change. Evaporate gently to dryness.

2. Add 75 m $6 \mathrm{~N}$ nitric acid to the flask and heat gently until all solids are dissolved.

3. Transfer the solution to a $250 \mathrm{ml}$ beaker, washing the flask with water; take to dryness gently on the hot plate. hour.

4. Muffle at $575^{\circ} \mathrm{C}$ for one

5. Add $60 \mathrm{ml} 2 \mathrm{~N}$ nitric acid to the beaker and heat to boiling until sample is dissolved.

6. Cool the sample to room temperature and add approximately one gram of hydroxylamine hydrochloride; stir until dissolved.

7. Transfer to a $100 \mathrm{ml}$ lusteroid centrifuge tube using 2N nitric acid as wash solution; the total volume at this point should not exceed $70 \mathrm{ml}$.

8. Add 1 ml lanthanum nitrate solution and bring the volume to $75 \mathrm{ml}$ with $2 \mathrm{~N}$ nitric acid. Stir the solution thoroughly.

\section{Procedure Notes}

It is absolutely necessary that all organic matter be completely oxidized.
Addition of hydroxylamine insures the absence of hexavalent plutonium.

\footnotetext{
Lanthanum nitrate solution may be prepared by dissolving. 6.2 of lanthanum nitrate hexahydrate in $100 \mathrm{ml}$ of $1 /$ nitric acid; this will furnish 20 ms lanthanum per milliliter.
} 
Procedure

9. Add 7 ml conc. hydrofluoric acid and stir thoroughly.

10. Allow to stand 2 minutes, stir and remove stirring rods by washing with small amounts of water, allowing the water to drain into the tube.

11. Let sample stand $3 \mathrm{mi}-$ nutes, then centrifuge sample and carefully decant the supernate completely.

12. Slurry the precipitate with \&N nitric acid; add 6-8 $\mathrm{m}$ I water and stir vigorously.

13. Add $2 \mathrm{~N}$ nitric acid in small portions until the volume is 75 ml, stirring we 11 between each addition.

14. Reprecipitate the lanthanum fluoride by adding $7 \mathrm{~m} \mathrm{I}$ conc hydrofluoric acid.

15. Repeat Steps 10 and 11 in that order.

16. Macerate the precipitate with the glass stirring rod. Add $2 \mathrm{ml}$ of aluminum nitrate solution and stir thoroughly to eliminate the large lumps.

17. Add $38 \mathrm{ml}$ more of the aluminum nitrate solution in increments of five to ten ml, stirring we 11 between each addition.

18. Transfer the solution to a separatory funnel; wash the stirring rod with $5 \mathrm{ml}$ of water, allowing the wash water to drain into the centrifuge tube; pour into the separatory funnel; wash down

$\underline{\text { Procedure Notes }}$ 


\section{Procedure}

the sides of the centrifuge tube with $5 \mathrm{ml}$ of water and pour into the separatory funnel.

19. Place the separatory funnel on a mechanical shaker, add $0.25 \mathrm{ml}$ sodium nitrite solution swirl to mix, and allow to stand for 15 minutes.

20. Add 10 ml of TTA solution and shake for 20 minutes.

21. Allow to stand until the phases are completely separated; discard aqueous phase.

22. Add $20 \mathrm{ml}$ water to the separatory funnel and shake for ten minutes; allow phase separation and discard the aqueous phase.

23. Add $10 m 1$ water and repeat Step 22.

24. A $1110 \mathrm{~m} \mathrm{I}$ of $8 \mathrm{~N}$ hydrochloric acid to the separatory funnel and shake for twenty min.

25. Allow liquids to separate and drain the hydrochloric acid into a $20 \mathrm{~m} /$ beaker.

26. Add $5 \mathrm{ml}$ of $8 \mathrm{~N}$ hydrochloric acid to the separatory funnel and shake for $10 \mathrm{~min}$.

27. Repeat Step 25.

28. Slowly evaporate the solution in the $20 \mathrm{ml}$ beaker to a volume of about $1.5 \mathrm{ml}$. Do not allow to boil or go dry. $\underline{\text { Procedure Notes }}$

Sodium nitrite solution is prepared not more than fifteen minutes before use by dissolving 1.2 of sodium nitrite in $10 \mathrm{ml}$ of water.

TTA solution is prepared by dissolving 5.0 of thenoyltrifluoroacetone in $100 \mathrm{~m} \mathrm{I}$ of benzene. 
29. Cool and add on potassium hydroxide until a pale reddish brown color appears.

30. Add $5 \mathrm{ml}$ of $2 \mathrm{fr}$ potassium hydroxide and $2 \mathrm{~m} \mathrm{I}$ of sodium hypochlorite solution.

31. Evaporate slowly to half the original volume.

32. Transfer to an electrodeposition cell, washing the beaker once with $1 \mathrm{ml}$ of sodium hypochlorite solution and three times with water.

33. Connect cell to the electrodeposition apparatus and electrolyze for five hours at 80 milliamps and 12 volts.

34. Remove cells from the apparatus without interrupting the current; discard the solution.

35. Remove the stainless steel disk from the apparatus, wash with water, allow to airdry, and flame lightly.

36. The plate may now be counted electronically or examined by radioautography .
Sodium hypochlorite is the ordinary commercial product containing 5 per cent available chlorine.

The electrodeposition cell is shown in Fig. 1. 
PROCEDURE C.

The following short procedure for the rapid isolation of plutonium should be used only to evaluate suspected acute exposures to the element 4 . It is not to be used for routine examination of urines.

\section{Pracedure}

1. Place the urine sample (200 $\mathrm{ml}$ or less) in a 2 liter Erlenmeyer flask, add $20 \mathrm{ml}$ conc nitric acid, $40 \mathrm{mg}$ lanthanum carrier, and evaporate to about $50 \mathrm{ml}$. Cool under running water, pour into a $100 \mathrm{ml}$ lusteroid test tube containing $25 \mathrm{ml}$ of $2 \mathrm{~N}$ hydrofluoric acid, and stir.

2. Allow the sample to stand two minutes, centrifuge two min., discard the supernate, and dissolve the precipitate in $50 \mathrm{ml}$ of $2 \mathrm{~N}$ nitric acid. Add $5 \mathrm{ml}$ of conc. hydrofluoric acid and stir. Allow the sample to stand two minutes, centrifuge two minutes, discard the supernate and dissolve the precipitate in $20 \mathrm{mI}$ of $2 \mathrm{~N}$ aluminum nitrate solution which is $0.45 \mathrm{~N}$ in nitric acid.

3. Place the solution in a $120 \mathrm{ml}$ separatory funnel containing $10 \mathrm{~m} \mathrm{I}$ of $0.45 \mathrm{M}$ TTA (Thenoyltrifluoroacetone) in benzene and shake for 10 minutes. Discard the aqueous phase and wash the organic phase with two 5 ml portions of $2 N$ nitric acid, two minutes each.

4. Evaporate the organic layer to a small volume, transfer to a suitable counting dish or planchet and evaporate to dryness under a heat lamp. Wash the beaker with two $1 \mathrm{ml}$ portions of benzene and evaporate these also. The sample is now prepared for counting. $\underline{\text { Procedure Notes }}$

It is not necessary that ashing be complete, since the serial lanthanum fluoride precipitations remove most of the organic matter.

$0.45 \mathrm{M}$ TA is prepared by dissolving 100 of TTA in a liter of benzene.

The four steps indicated here should average about fifteen minutes apiece; the sample is thus prepared for counting in about an hour. 


\section{Counting Procedures}

A. Electronic counting is carried out on conventional proportional counters capable of continuous operation with backgrounds in the neighborhood of 3 counts per hour. Simple statistical methods must be used to evaluate the probable errors involved in counting periods of various lengths.

B. Counting by radioautography offers a real advantage over electronic counting in that very long counting periods may be utilized and that backgrounds are almost vanishingly low. In this technic, the thin films of radioactive material (mounted on stainless steel discs) are allowed to stand in a camera (Fig. 2) for one week at $5^{\circ} \mathrm{C}$ in contact with NTA-25 nuclear plates. The plates must previously have been cleared of background grains and tracks by treatment with hydrogen peroxide vapor and subsequent desiccation. Following exposure, the nuclear plate is removed fromthe camera and developed, fixed, and washed by more or less conventional photographic developing procedures. Examination of the exposed and developed nuclear plate reveals the presence of tracks of silver grains; the number of these tracks is a function of the number of alpha particles which have contacted the sensitive emulsion. Appropriate calculations regarding the fraction of the exposed area examined, the number of tracks, the exposure time, and the film efficiency (determined by running standard sources) afford a measure of the amount of radioactive material present. For details of the construction and operation of the accessory apparatus necessary, the work of the original authors should be consulted 2,3 . 
IV. Bibliography

1. Schubert, J., L.S. Myers, Jr., and J.A. Jackson.

"The Analytical Procedures of the Bio-assay Group at the Argonne National Laboratory." USAEC ANL-4509, pp. 5-8 (March, 1951).

2. Schwendiman, L.C., J.W. Healy, and D.I. Reid.

"The Application of Nuclear Track Emulsions to the Analysis of Urine for very LOW Level Plutonium." USAEC BH-22680 (November, 1951).

3. Schyendiman, L.C., and J.W. Healy.

"Nuclear Track Technic for Low Level Plutonium in Urine." Nucleonics, 16 (6), 78, 80-2 (1958).

4. Unpublished data. Hanford Atomic Products Operation, Richland, Washington. 


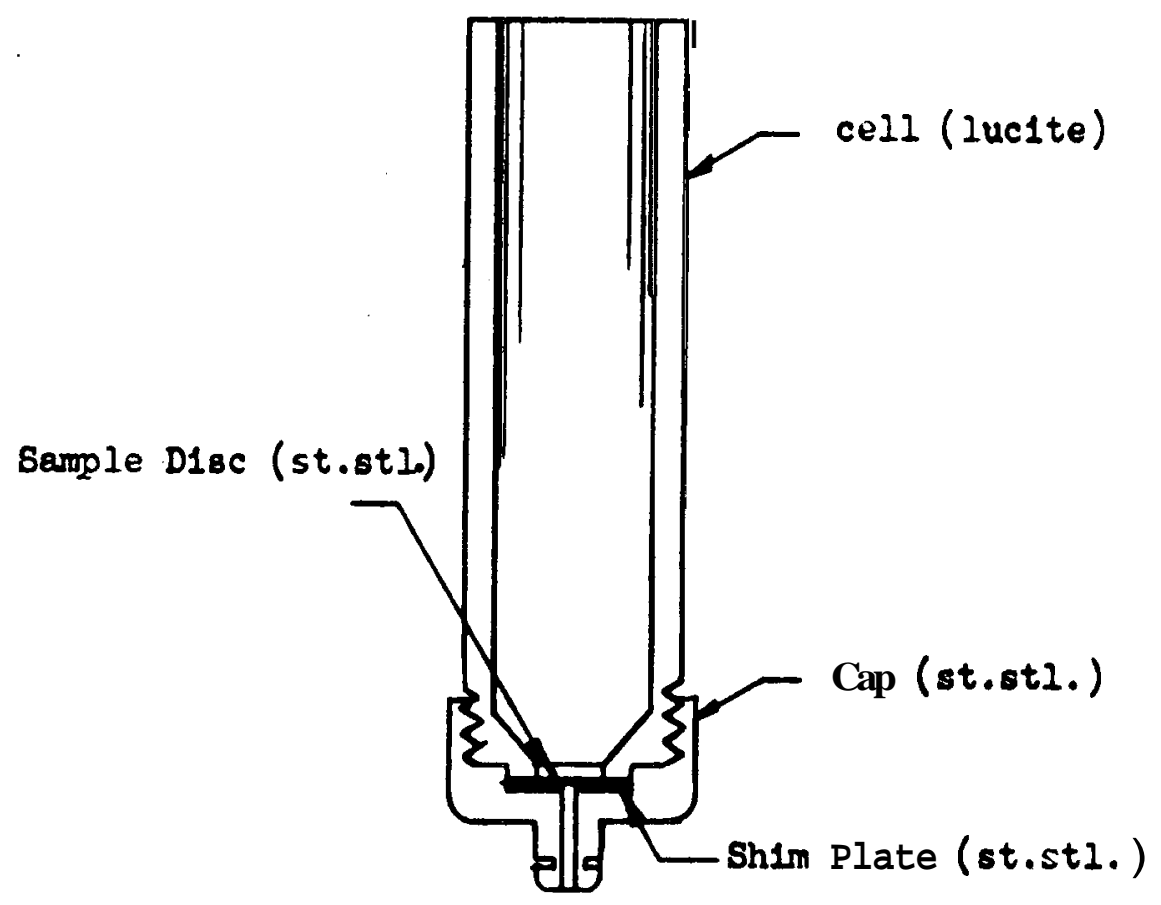

Fig. I ELDCTRODEPOSITION CEIL ASSEDBLY-8ECTION 


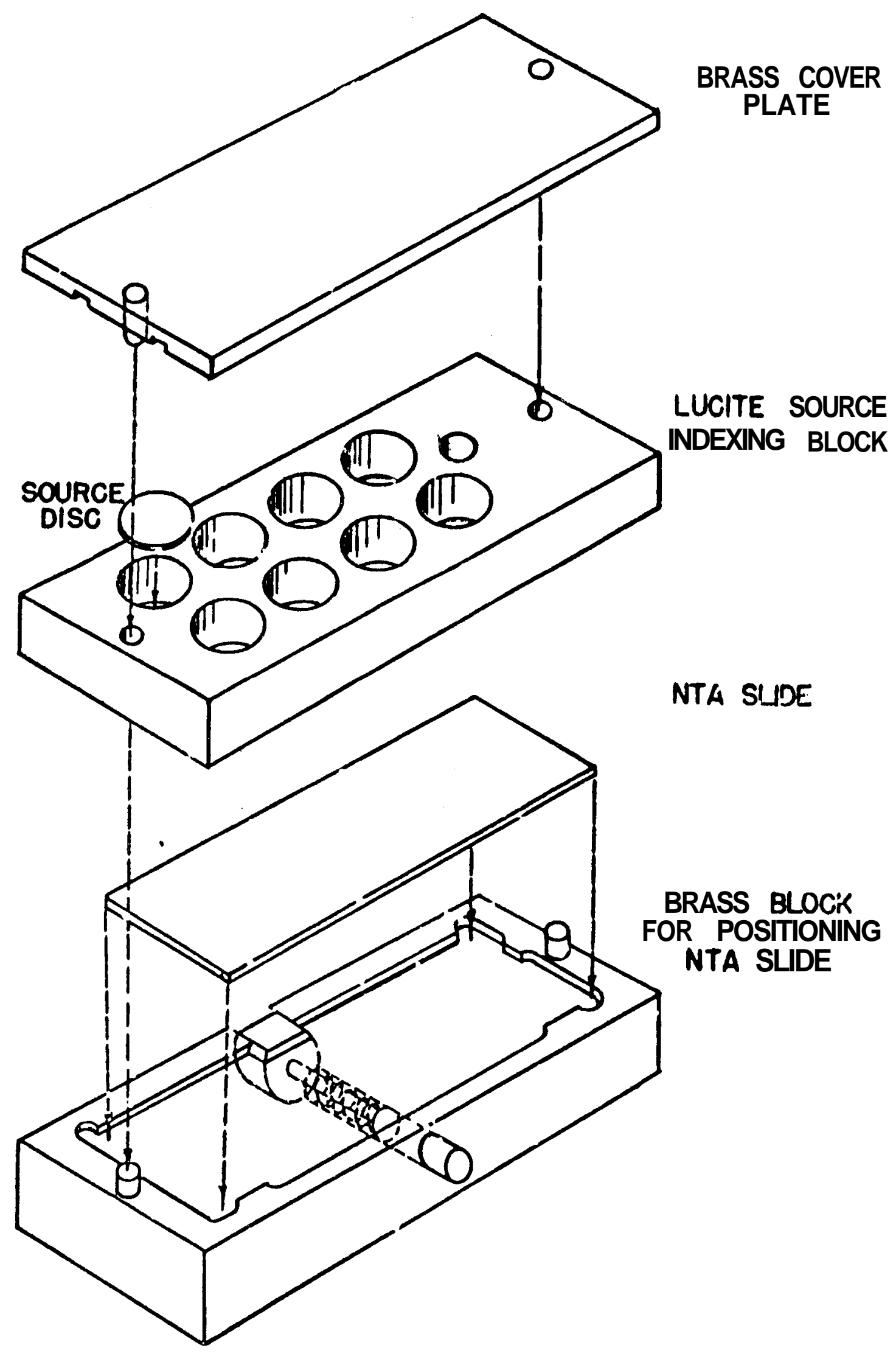

FIQ 2 RADIOAUTOGRAPAHO GAMERA 
Recommended Bio Assay for Polonium

Reviewer -- Robert G. Thomas

August 1958

URTRALYSTS WTTHOUT DIGSSTION

I, For personnel engaged in routine work with polonium weekly samples are generally required. The specimen is usually collected during the morning of the first day of the work week. The sample size must be at least $100 \mathrm{ml}$; one-half pint Seslrite contsiners are suitable. If more than one hour is to elspse between collection and analysis the speciat should be preserved with sulfamic acid ( $1 \mathrm{mg} / \mathrm{ml}$ urine) and stored at $3^{\circ} \mathrm{C}$. For personnel routinely enged in very low level operations with polonium the collection period be extended to sem-montbly or monthly.

II. Procedure

1. Measure $100 \mathrm{ml}$ of sample with a graduate and transfer to a $150 \mathrm{ml}$ beaker.* Rinse with $20 \mathrm{ml}$ $6 \mathrm{~N} \mathrm{HCl}$ and add to urine.

2. Place sample in temperature bath at $50-55^{\circ} \mathrm{C} . *$

3. Degrease a nickel disk in conc, $\mathrm{HNO}_{3}$, rinse in distilled $\mathrm{H}_{2} \mathrm{O}$, dip in concentrated $\mathrm{HCl}$, and rinse in distilled $\mathrm{H}_{2} \mathrm{O}$. (Disks made of 0.025 inch "commercial pure nickel sheet. Have $7 / 8^{\prime \prime}$ diameter with a $1 / 8^{88}$ hole set $1 / 16^{81}$ in from edge.)

4. Suspend disk on a glass stirring hook in urine preparation and stir for one hour at a speed giving maximum agitation with minimal splashing.

5. Remove disk from urine, rinse down stirring rod and disk with distilled $\mathrm{H}_{2} \mathrm{O}$ and $\mathrm{let}$ dry in air.

6, Count alpha activity with a low background proportional

\section{$\underline{\text { Procedure Notes }}$}

1. Acid is added in this proportion to bring the entire sample to $1 \mathrm{~N}$ in $\mathrm{ECl}$.

2. Subsequent plating is most efficient at elevated temperatures.

3. Degreasing necessary to get maximum plating surface for electrochemical exchange.

4. Without proper agitation the plating time has to be extended considerably and efficiency of deposition is decreased.

5. Rinsing minimizes the possibility of absorption of the alpha particles by foreign matter.

6. After subtracting background the activities from the

An alternate procedure involves plating from a waxed drinking cup at room temperature, This necessitates a prolonged plating time but enables discarding the container when plating is complete. 
counter on each side for 30

minutes two sides may be added or averaged multiplied by two.

\section{ACCURACY AND SENSITIVITY OF METHOD}

Analysts are advised to run periodic spiked samples and blanks together with their experimental samples。 Most laboratories utilizing this method (or slight variations of $i t$ ) report a recovery of about $90 \%$ in the range of 10 to $1000 \mathrm{dis} / \mathrm{min} / \mathrm{liter}$ for analyses on $100 \mathrm{ml}$ of urine.

\section{URINE AND TISSUE ANALYSIS WITH DIGESTION}

I, Urine collection may be made on a 24-hour basis since this method will enable handling of at least one liter. Therefore, collection is recommended for the 24-hour period ending at the start of the first working day of the week. Fecal collections may be on the same 24-hour schedule; both collections may be made in one quart Mason jars. Tissue samples should preferably be kept under 500 grams.

I.

\section{Proceciure}

1 Place solid samples in a digestion vessel of such capacity that sample is $10-20 \%$ of the volume. Digestion may be carried out in Erlenmeyer flasks or beakers. Urine samples may constitute $30 \%$ of volume capacity - a s mall vessel may be used and urine added as evaporation progresses.

2. Add $2 \mathrm{ml}$ of concentrated $\mathrm{HNO}_{3}$ for each gram of solid material up to 50 grams and $1 \mathrm{~m} \mathrm{I}$ for each gram over this, Allow to stand for several hours or overnight at room terto. Add conc. HM03 to urine of the order of $50 \%$ by volume. Standing overnight is not necessary for urine samples 。

3. Place vessel on hot plate and gradually increase temperature to boiling. Use glass beads if bumping occurs and Dow Antiform as needed to prevent excessive foaming. Heating is continued at a smooth boil until digest is a clear yellow color, Take to

\section{$\underline{\text { Procedure Notes }}$}

1. In the subsequent digestion some foaming and spattering may occur and a comparatively large vessel is required.

2. If heat is applied without an extended period of slow digestion at room temperature, excessive foaming and loss of sample is very likely to occur.
3. Organic material in hot nitric acid is oxidized fairly easily. Fat takes longer than carbohydrate or protein and may be used as an indicator for completion of digest。 
minimum volume, add $25 \mathrm{~m} \mathrm{l}$ of water and observe. If clear, digestion is complete; if not, presence of $\mathrm{fat}$ is indicated and digestion should be continuede

4. Take digest (now at minimal volume or containing $25 \mathrm{ml}$ 피) to neutrality with NaOH (a saturated solution may be used). Then make to $0.5 \mathrm{~N}$ with concentrated HCl. Transfer to a plating bottle with 3 rinses of $0.5 \mathrm{~N} \mathrm{HCl}$ and add sufficient $0.5 \mathrm{~N} \mathrm{HCI} \mathrm{to} \mathrm{bring}$ to $100 \mathrm{ml}$.

5. A $100 \mathrm{mg}$ tablet of ascorbic acid is added if iron is known or suspected to be present.

6. Place plating column in water bath at $90-100^{\circ} \mathrm{C}$ and stir for 90 minutes at a rate for maximum agitation with minimal splattering,

7. Remove silver plate, rinse, dry and count on low background proportional counter.
4. Plating on silver is most efficient at a normality of 0.5 in $\mathrm{BCl}$. Neutralization is necessary because the acid remaining after digestion may be very concentrated.
5. Ascorbic acid is used to reduce $\mathrm{Fe}^{++t}$ ion which Interferes with plating.

6. These conditions give maximum efficiency for electrochemical deposition on silver.

7. Rinsing and drying necessary to minimize absorption of alpha particles by remaining residue.

NOTE: A faster and more efficient digestion be performed using a combination of perchloric acid and nitric acid. (See reference (I), and reference (5) for details.) However, this on occasion has led to explosive mixtures unless one is experienced and meticulous with perchloric acid, and it is therefore not recommended for routine procedures.

\section{ACCURACY AND SENSITIVITY OF METHOD}

Digestion of most biological samples requires considerable practice before the method can be employed routinely with consistent results. Reported recoveries are in general about $90 \%$ over an \&lmost unlimited range of radioactivity.

\section{Illustrations of Special Equipment}

1. Baby bottle column for plating。 (Figure I)

2. Plating bath. (Figure 11) 


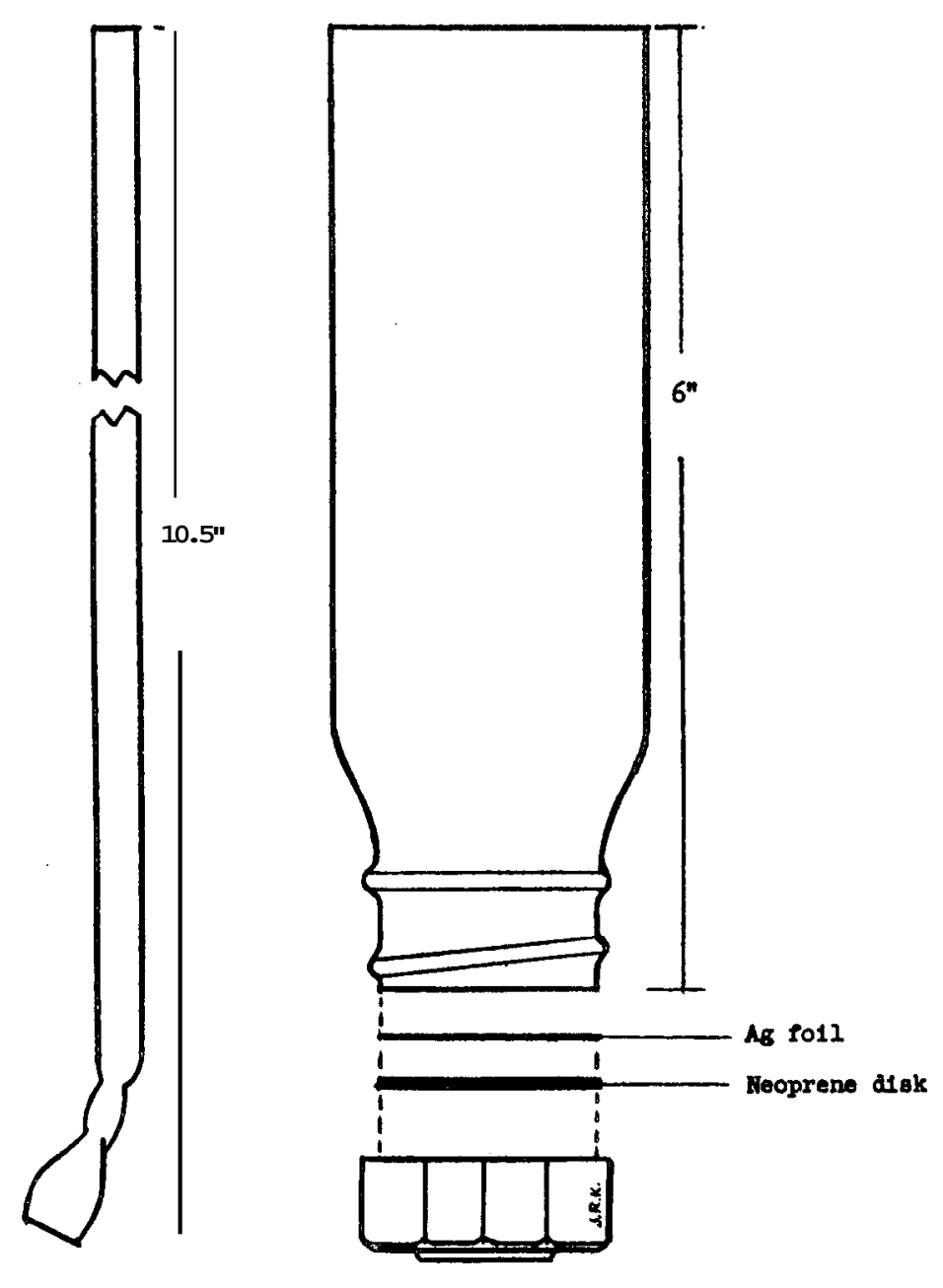

Figure I. Plating bottle and stirring rod. Davol brand nursing bottles with the bottom cut off. A $1 / 16^{\prime \prime}$ neoprene disk and .005" silver foil fit inside the cap which is then firmly screwed onto the bottle. The stirring rod is $1 / 4^{n}$ glass with the bottom heated and squeezed with tongs to make two $1 / 2^{\prime \prime}$ oval flats at right angles to each other and bent to a Line approximately $30^{\circ}$ from centerline of rod. 


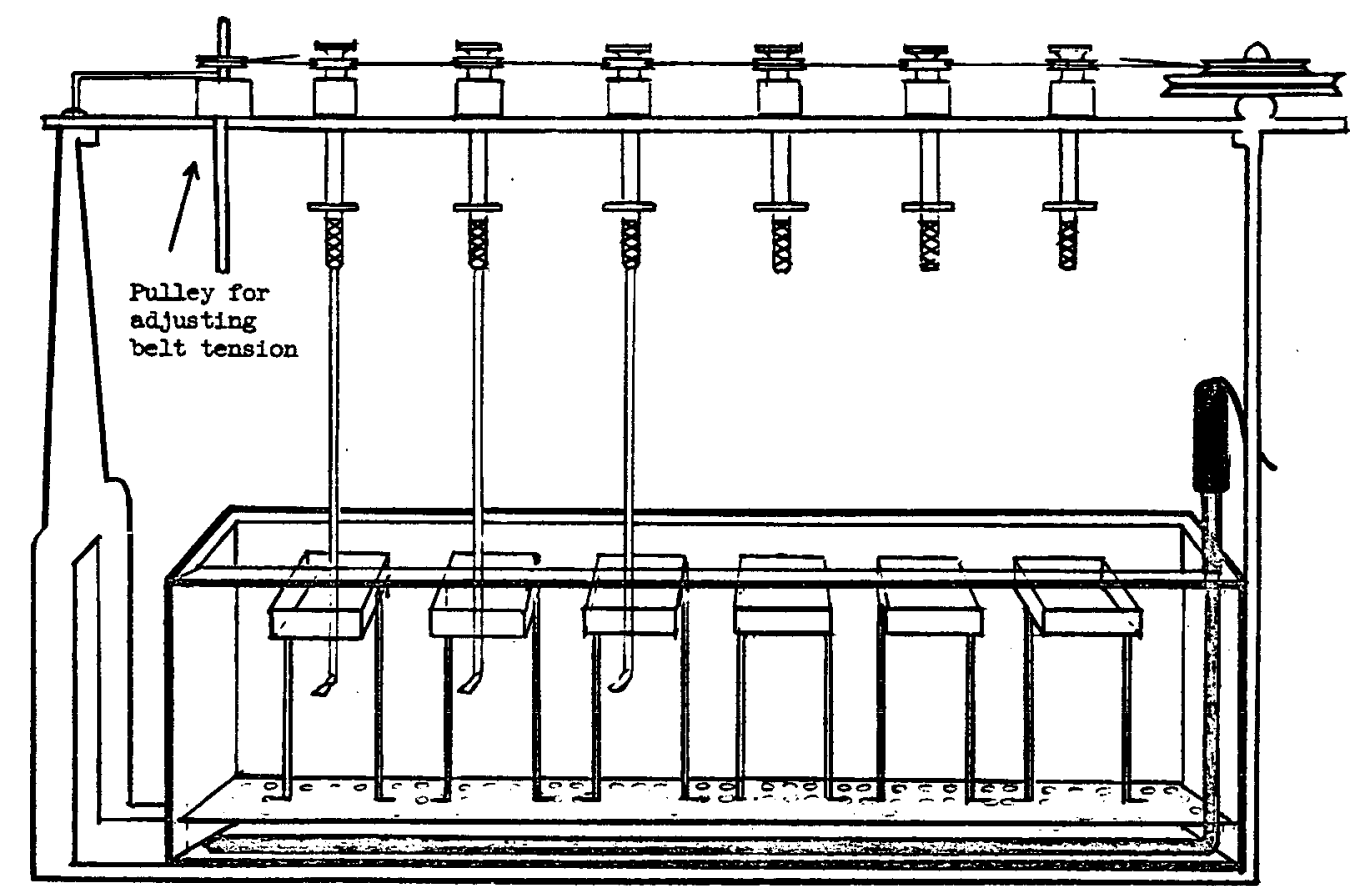

Figure II. Plating equipment -- the individual stirrers are mounted in a frame constructed of $1 / 4^{\prime \prime} \times 2^{\prime \prime}$ steel, the water bath is a box made of $1 / 2^{\prime \prime}$ plywood lined with 20 gauge copper, \& $1 / 4 "$ transite board in the bottom supports the 1000-watt electricalheater on which rests a 20 gauge copper plate with supports for positioning the plating bottles. The stirre. collets are mounted on shafts through roller bearings. The stirrers are belt driven by a variable-speed electric motor. 
III.

1. Recommend 24-hour urine and fecal samples daily for ten days. Thereafter urine samples weekly are sufficient to estimate the body burden.

\section{Bibliography}

1. Baxter, Robert and Wood, De Witt. Apparatus for plating out polonium for analysis. UR AEP Report, UR-269.

2. Black, Stuart C. Low level polonium determination of tissue and urine. UR ABP Report, UR-463.

3. Meyer, Herbert E. Polonium determination in urine, feces, and blood. Proceedings of the Second Annual Meeting on Bio-Assay and Analytical Chemistry, WASH-736.

4. Robbins, M. Chain. The determination of polonium in urine. Ios Alamos Scientlfic Laboratory Report, LA-1904.

5. Smith, Frank A., Della Rosa, R. J. and Casarett, L. G. Analytical and autoradiographic methods for polonium210. UR ARP Report, $\underline{\mathrm{UR}-305}$.

6. Smith, G. Frederick. Mixed perchloric, sulfuric and phosphoric acids and their application in analysis. Second edition, G. Frederick Smith Chemical Co., Columbus, Ohio, 1942. 
Recommended Bio Assay for Radium

Reviewer -- John B. Hursh

September, 1958

BODY CONTENT MONIIORING FOR RADIUM LOADS

I N THE RANGE $\geq 0.01 \mu c$

I. By Radon Breath Measurement. The most satisfactory method of routine body content monitoring for Raz26 has been (1) and at present remains measurement of radon in the breath. Urine and fecal samples reflect recent exposure (2) and while the measurement of these excreta may serve as an adjunct for environmental control, it does not adequately determine body content in the general case.

\section{A. COULCTION OF BREATH RADON}

Procedure

1, Stipulate that the subject has been away from an elevated radon atmosphere for 48

hours. Subject comes to an offplant site for sample collection.

2, The subject is seated and at rest. Pulse and resgiratory rate should be normal.

3. The subject is fitted with a face mask of low resistance to air passage and the expired air is collected in a large balloon (such as a meteorological balloon) for a breathing period of 3 minutes,
Procedure Notes

When the subject goes from the elevated radon atmosphere of the plant to a radon clean atmosphere the environments 1 radon dissolved in the body tissues is blown off. The fat reservoir empties quite slowly (3). The 48 hours suggested is arbitrary. It would usually be sufficiently long to make the plant radon residue in the breath negligible with respect to the radon formed in the body for body radium contents in the range of interest.

Since you propose to determine the rate of production of radon from radium in the body, it is desirable that the rate of transfer of radon from one body compartment to another and into the breath be in a steady state.

Low air resistance is essential to preserve normal breathing rate. 
Procedure

Procedure Notes

The balloon must be able to hold at least 30 liters without stretching the rubber.

4. The air sample is collected for shipment to the measurement laboratory. This is customarily done in a 2stopcock spherical pyrex glass bulb of 1 liter capacity. The bulb may be attached to the filled balloon with a gas meter or other measurement device connected to the output stopcock of the bulb. The balloon is then compressed so that the entire gas content passes through the bulb and the total volume is measured by the gas meter. The stopcocks are then closed and the bulb labelled and placed in the shipping container.

5. A hand pump or other convenient device is used to collect a sample of the room air in a comparable breath bulb.
The intent is to collect a 1 liter sample of representative breath. In order to find the rate of radon escape in the breath the total air volume exhaled in $\mathbf{3}$ minutes must be measured.

\section{B. SAMPLE MEASUREMENT}

For sample measurement it has been customary for radium handling plants to ship the breath bulbs to a service laboratory* specializing in the low level radon analysis. Descriptions of handling techniques and electronic equipment may be found in the literature $(4,5)$.

This analysis is performed by Robley D。Evans, 77 Massachusetts Ave., Cambridge 34, Massachusetts. Analyses for Federal and State governments are performed by the Radioactivity Section, National Bureau of Standards. Both laboratories furnish sampling flasks and instructions, and will auote their charges upon inquiry. 


\section{C。 INTERPRETATION OF ANALYTICAL RESULT}

1. The laboratory report in $\mu \mu c$, of radon per liter breath must be decay-corrected to time of collection. If not already corrected by the analytical laboratory:

$$
A_{0}=\frac{A_{t}}{e^{-0.181 t}}
$$

Where: $A_{0}=\mu \mu c$ radon/liter at time of collection.

$A_{t}=H$ He radon/liter at time of measurement.

$\mathbf{t}=$ time from collection to measurement in days。

2. Since 70 percent of the radon formed in the body from long standing radium loads is eliminated in the breath (6), the radium body content may be calculated if the radon expired per unit time is known.

$$
Q_{R a}=\frac{A_{0} \cdot V}{88}
$$

Where: $Q_{R a}=$ body content of $R a^{226}$ in $\mu_{c}$ 。

$$
\begin{aligned}
A_{O}= & \mu H_{c} \text { Rn per liter expired air. } \\
V \quad= & \begin{array}{l}
\text { ventilation rate in liters per } \\
\text { min. }
\end{array}
\end{aligned}
$$

\section{Alternative Methods.}

1. Ra226 body content may be conveniently measured in a whole body counter (7) if this special facility is available.

2. If adequate laboratory facilities are available and it is desired to make measurements on the site, adsorption of the breath radon on charcoal at low temperatures $(8)$, or at room temperatures (9), may be the method of choice, The radon is removed from the charcoal by heating and is flushed into an ionization chamber for measurement. With some refinements this general method may be extended to measurement of the small quantities of radium naturally present $\left(10^{-10}\right.$ curies) in occupationally unexposed subjects (10). 


\section{Bibliography}

1. Evans, R.D. Protection of radium dial workers and radiologists from injury by radium. Jo Indust. Hyg. and Tox. 25, 253-269 (1943).

2. Hursh, John B. The limitations of urinary radium as a measurement of radium body load. UR AEP Report, UR-522 (1958).

3. Harley, J.H., Jetter, E. and Nelson, N. Elimination of radon from the body. dew York Operations Office AEC Report No 3 (1951).

4. Hursh, John B. and Gates, A.A. Body content of individuals with no known occupational exposure. Nucleonics 7 , No. 1, 46-59 (1950).

5. Sadowski, H., Gravson, R. and Levine H. A low level radon counter. New York Operations Office Report (to be published).

6. Norris, W.P., Speckman, T.W., and Gustafson, P.F. Studies of metabolism of radium in Am. J. Roentgenol., Rad. Therapy and Nuclear Med。 73 785-802 (1955).

7. Miller, C.E. and Marinelli, L.D. The game-ray spectrum of normal human beings. Radiology 66, 104-105 (1956).

8. Stehney, A.F., Norris, W.P., Lucas, H.F., Jr., and Johnston, WH. A method for measuring the rate of elimination of radon in breath. Am. J. Roentgenol., Rad. Therapy and Nuclear Med. 23, 774-783 (1955).

9. Hursh, J.B. Measurement of breath radon by charcoal adsorption. Nucleonics 12, No. 1, 63-65 (1954).

10. Stehney, A.F., and Lucas, H.F. Studies on the radium content of humans arising from the natural radium of their environment, Proceedings Int. Conf. on Peaceful Uses of Atomic Energy, Vol. 11, 49-54, United Nations, New York (1956). 
The assay of excreta, urine, tissue samples, food and water for radium 226 is in general done by alpha counting. The preparation of samples from the raw material involves digesting and prepsing a clear solution. If Ra226 is the only radium isotope of 1nterest, the analyst has the choice of deemansting the solution, permitting radon to build up for a known time, collecting radon, and measurement in any convenlent way; or of separating radium out by coprecipitation techniques, depositing it as a very thin layer on a counting planchet, and counting in a gas flow counter, The second method should be used if all radium isotopes are to be accounted for. Reference has been made above to equipment and special procedures used in radon measurement. The chemical analytical technique will be described in detail below, For routine samples an overnight urine collection may be requested. The specimen container should be guarded against contamination. The elimination rates per day may be calculated assuming $1500 \mathrm{ml}$. as a daily urine output.

\section{Method for Urine.}

Procedure

1. Place a convenient volume of a sample in an 800 $\mathrm{m}$ I beaker covered by a ribbed watch-glass and heat gently on a hot plate, As the volume decreases add additional amounts of urine until all the sample has been transferred. Reduce to a volume of about $100 \mathrm{ml}$.

2. Cool, add 50 ml conc. analytical grade nitric acid. Evaporate to dryness on the hot plate.

3. Repeat Step 2, until the residue is white. As digestion nears completion a smaller amount of nitric aoid may be added.

4. Add $150 \mathrm{~m} \mathrm{I}$ of $0.1 \mathrm{M} \mathrm{BN}_{3}$ to the residue and warm for 5 minutes. Transfer the solution and any ss-yot-andissolved residue to a $250 \mathrm{~m}$ I centrifuge bottle. Save the beaker.

\section{$\underline{\text { Procedure Notes }}$}

Add glass beads if necessary to prevent bumping.
Nitric acid should be added cautiously to avoid sample loss by excessive foaming.

A the completion of this stage the organic matter has been oxidized.

Step 4, 5, and 6, wi 11 usually get all the radium into solution as nitrate, If the residue in step 6 is large, it should be spot checked for alpha activity. 
$\underline{\text { Procedure }}$

5. Centrifuge and decant the supernatant into a second $250 \mathrm{ml}$ centrifuge bottle, Retain solution and residue.

6. Wash the original beaker with $50 \mathrm{ml}$ of $0.1 \mathrm{M}$ सrO3. Add the wash solution to the first centrifuge bottle, stir, and centrifuge. Decant the supernatant into the second centrifuge bottle. Discard residue.

7. Place the second centrifuge bottle in an ice bath and stir the solution vigorously with an electric stirrer. Add $3.0 \mathrm{ml}$ of conc. sulfuric acid. Add 0.5 mI of lead nitrate $(200 \mathrm{mg}$. $\mathrm{Pb} / \mathrm{ml}$ ) drop-wise. Continue stirring for 15 minutes.

8. Centrifuge and discard supernatant. Add $15 \mathrm{ml}$ hydrochloric acid-ether reagent (6 volumes conc. hydrochloric acid plus 1 volume diethyl ether). Wam slightly to increase the rate of dissolution of the lead sulfate.

9. Transfer the solution to a $50 \mathrm{ml}$ centrifuge tube using a total of $10 \mathrm{ml}$. of HCl-etber reagent to rinse the centrifuge bottle.

10. Cool the solution in an
Procedure Notes

Lead is used as a carrier to precipitate radium as the sulfate. Lead is used rather than barium since the solution volume is large and therefore a correspondingly large amount of carrier is required, and since lead can be separated from radium later, whereas barium can not be conveniently separated. Less than 10 percent of the uranium, protactinium, and thorium isotope present are carried by lead sulfate. The lead sulfate precipitation is made from a large volume $(200 \mathrm{ml})$ t o avoid precipitation of calcium sulfate.

Lead sulfate (plus radium sulfate) are soluble in the HClether solution. This step also may serve to reduce the amount of sulfate (present in digestion solutions of some biological samples) carried to later steps, permitting the later precipitation with barium as predominately the chloride,

The addition of barium carries 


\section{Procedure}

ice bath and stir with an electric stirrer, Add $0.4 \mathrm{ml}$ barium nitrate solution (10 mg $\mathrm{Ba} / \mathrm{ml}$ ) dropwise and continue stirring for 5 minutes. Do not perform this precipitation unless the analysis can be completed and the sample counted the same day.

11. Centrifuge and discard the supernatant. Dissolve the barium chloride precipitate in $5 \mathrm{ml}$ of distilled water. Add 1 $\mathrm{ml}$ of $0.5 \mathrm{M} \mathrm{H}_{2} \mathrm{SO}_{4}$ dropwise with stirring. Stir for 15 minutes.

12. Centrifuge, discard the supernatant. Wash precipitate with $5 \mathrm{ml}$ of distilled water, centrifuge and discard wash water 。

13. Transfer quantitatfvely the barium sulfate precipitate with distilled water to a stainless steel counting planchet。 Spread the precipitate uniformly over the planchet, Evaporate to dryness under a heat lamp.

14. Flame the planchet (note time), and count in a low-background alpha counter. To determine the nuclide or nuclides
Procedure Notes

radium out of solution if stirring is rapid and complete since radiumbarium chlorides are relatively insoluble in conc. $\mathrm{HCl}$. The presence of ether serves to further depress the solubility. In this step Ra is separated from its $\mathrm{Pb}$, Po, and B i daughters, and the amount of carrier is reduced from 100 mg of lead to 4 ms of barium., The counting plaque should be prepared and measured forthwith since it is desired to count the radium alpha alone so that the activity measurement may be interpreted in terms of radium concentration.

The transformation to the sulfate is performed since it is possible to more easily obtain a thin uniform layer on the counting planchet than when a solution of barium chloride is dried 。

The stainless steel planchet should be approximately 2 inches in diameter, so as to keep self absorption minimal. If it is found necessary to restrain the liquid transfered, a thin border of Zapon laquer may be $1 \mathrm{a}$ id around the circumference and dried before the liquid transfer.

This is burned off in the flaming process in step 14 .

Flaming drives off the radon daughter of Ra226. From this time radon will be built into the sample and retained by 
Procedure

present, count the sample again after 1, 3, 7, and 10 days.
Procedure Notes

adsorption on or inclusion in the precipitate, If the sample contains only $\mathrm{Ra}^{226}$ the count will grow with the halftime of 3.825 days to a final equilibrium value four times the initial count, The plot of activity growth may thus be used to identify the radium isotope.

II. Feces

1. Transfer sample to a tared porcelain crucible of appropiate size and dry overnight in an oven at about $120^{\circ} \mathrm{C}$.

With high water content samples, care must be taken to avoid spattering and sample loss, In such cases it may be advisable to carry out the first part of this step over a hot plate at low heat in the hood, watching to avoid charring.

2. Remove crucible from the oven, cool, and weigh. Place the crucible in a muffle furnace and ash at $600^{\circ} \mathrm{C}$. Allow to cool, transfer to a beaker, add sufficient nitric acid to cover the sample and evaporate to dryness.

3. Repeat step 2 until the residue is white.

4. Add $24 \mathrm{ml}$ of $6 \mathrm{~N} \mathrm{HCl}$ and evaporate just to dryness.

5. Add $10 \mathrm{ml}$ of conc. nitric acid washing down the sides of the beaker with the acid and evaporate to about $2 \mathrm{ml}$.

6. Repeat step 5 two more times。

7. Complete the analysis beginning with step 4 of the procedure for urine. 
III. Sensitivity and Reproducibility, radium.

1. The practical limit of this method is judged to be 10-13 grams

2. Using this method overall recoveries of spiked urine samples containing from $1.4 \times 10^{-12}$ to $1.5 \times 10^{-9}$ grams radium, have been reported (3) of $98+1 \%$. Other users, spiking tissue samples, including bone, have found recoveries of 75 to $80 \%$. In this latter case the recovery deficit includes losses from self-absorption in the sample and any loss of radon which may occur, from the deposited radium sulfate, as well as radium losses in the process.

\section{Bibliography}

The method outlined above has drawn heavily on the following sources:

1. Ames, D.P., Sedlet, J., Anderson, H.H., and Kohman, T.P. Rapid radiometric assay for radium and application to uranium ore process solutions. Natl. Nuclear Energy Series, IV-14B, p. 1700: New York, MeGraw-Hill Book CO. (1949)。

2. Sedlet, J. Determination of micromicrogram quantities of radium. Proc. of Bio-Assay and Analytical Chemistry Meeting, National Lead Company of Ohio (Oct. 1955).

3. Russell, E.R., Lesko, R.C., and Schubert, J. A direct method for determining radium in exposed humans. Nucleonics I, 60 (1950).

4. Sedlet, J. (Personal Communication), 1958. 
Procedure

1. Add $\mathrm{NH}_{4} \mathrm{OH}$ to $200 \mathrm{ml}$ of urine in a $250 \mathrm{ml}$ centrifuge bottle until precipitation is complete ( $\mathrm{gH}$ about 7 ).

2. Centrifuge, discard supernatant liquid.

3. Wash precipitate with $25 \mathrm{ml}$ of $10 \% \mathrm{NH} 4 \mathrm{OH}$.

4. Centrifuge, discard supernatant liquid.

5. Dissolve the precipitate in a few milliliters of conc. acetic acid and add $200 \mathrm{~m} \mathrm{I}$ distilled water.

6. Bring the solution to a $p \mathrm{H}$ of 5.0 with $\mathrm{NH}_{4} \mathrm{OH}$ ( $p \mathrm{E}$ test paper).

7. Add 3 to $4 \mathrm{gm}$. of $\left(\mathrm{NH}_{4}\right)_{2}$ $\mathrm{SO}_{4}, 1 \mathrm{ml}$ of $0.015 \mathrm{M} \mathrm{BaCl} 2$ ( $2 \mathrm{mg}$ $\mathrm{Ba}^{++}$) stir well, digest overnight。

8. Filter through fine filter paper, wash with $0.5 \% \mathrm{H}_{2} \mathrm{SO}_{4}$, dis card filtrate.

9. Place filter paper with precipitate in a small platinum dish, ignite at $800-900^{\circ} \mathrm{C}$.

10. Add 2 ml of $50 \%$ by volume $\mathrm{H}_{2} \mathrm{SO}_{4}, 5 \mathrm{ml}$ of $48 \% \mathrm{HF}$, and evaporate on a sand bath until $\mathrm{SO}_{2}$ fumes appear.

11. Transfer to a $50 \mathrm{~m}$ I centrifuge tube with $40 \mathrm{ml}$ of distilled $\underline{\text { Procedure Notes }}$

The heavy metal group principally $\mathrm{Ca}$ but including $\mathrm{Ra}$ are precipitated as phosphates.

Since $\mathrm{Na}, \mathrm{K}$ and to some extent $\mathrm{Mg}$ form soluble salts they are discarded in the supernatant.

The heavy metal phosphates are readily soluble in acid.

To standardize $\mathrm{pH}$ for barium carrier precipitation, This adjustment is not critical from pH 1 to 5 .

Ba-Ra sulfates precipitate whereas calcium sulfate is soluble as well as any magnesium carried to this point,

Any organic matter carried along to this point is removed in this step,

This step disposes of silicates. The appearance of $\mathrm{SO} 3$ fumes indicates that all the Bᄑr acid has been vaporized.

11. - 14. Concerned with washing out acid and preparing 
Procedure

water and digest overnight.

12. Centrifuge and discard supernatant liquid.

13. Wash precipitate with $10 \mathrm{ml}$ of distilled water, centrifuge and discard supernatant liquid。

14. Wash precipitate with $10 \mathrm{ml}$ of $95 \%$ ethyl alcohol, centrifuge and discard supernatant liquid.

15. Transfer precipitate with ethyl alcohol onto a round nickel plate $2.8 \mathrm{~m}$ in diameter, and dry under an infrared lamp. $\underline{\text { Procedure Notes }}$

for plating.

16. count.

\section{SENSITIVITY AND REPRODUCIBILITY}

1. The $1 \mathrm{imit}$ of practical determination is considered to be 10-13 gm of radium (1) for a 60 minute count on units having a background counting rate less than $0.1 \mathrm{cpm}$ and a geometry of $40 \%$. Fifty percent of the tests should be within \pm 20 percent.

2. Using the above method in analyzing for radium added to urine from 0.068 to $1.360 \mu \mathrm{H} c$ an average recovery of 100 percent ras reported (1).

\section{Bibliography}

1. Harley, J.H. and Foti, S. Determinations of micromicrogram quantities of radium. Nucleonics 10, No. 2, 45-57 (1952). 
Recommended Bio Assay Procedures for Thorium

Reviewer -- George A. Welford

September 1958

I. Collection of Urine Samples. The following precautions are recommended for sample collection.

1. Collect a 24 hour urine sample in a polyethylene container.

2. Add a volume of hydrochloric acid as preservative.

3. Weekend samples should be obtained mine possible to avoid contamination.

4. A routine sampling program may consist of two 24 -hour urine samples per six month period.

5. In case of emergency exposure, spot samples should be taken regularly.

11. Accuracy and Sensitivity. The methods in the hands of the reviewer are capable of determining one microgram of thorium per liter of urine. The analysis of ten urine samples, with one microgram of thorium added, and carried through each method gave the following percent recoveries:

$$
\begin{aligned}
& \text { Method A }-92 \pm 14(1)-95 \pm 15(2) \\
& \text { Method B }-94 \pm 16
\end{aligned}
$$
(1) Chrome Azurol S.
(2) Morin. 


\section{Method A -. Thorium Assay of Urine}

\section{Procedure}

1. Pour measured volume of urine into a centrifuge bottle.

2. Adjust the or using ammonium hydroxide.

3. Centrifuge for $\mathbf{1 5}$ minutes. Decant and discard the supernatant liquid.

4. Dissolve the precipitate with 10-20 ml of concentrated $\mathrm{ENO}_{3}$. Transfer the solution to a 75 ml platinum crucible. Evaporate to dryness.

5. Wa ash the residue with several additions of concentrated $\mathrm{ZNO}_{3}$ and evaporate to dryness.

6. Dissolve the ashed residue in $100 \mathrm{ml}$ of $2 \mathrm{~N}$ BCl.

7. Adjust the pr of the solution to $4.0+0.1$ using sodium hydroxide.

8. Heat the solution to $95^{\circ} \mathrm{C}$, then add with stirring 4 mil of a $10 \%$ oxalic acid solution.

9. Stir vigorously until precipitate forms, allow the solution to cool to room temperature.

10. Filter by gravity through No. 42 Whatman paper.

11. Wash the Precipitate with a $10 x$ oxalic acid solution.

12. Transfer the filter and precipitate to a crucible. Dry at $110^{\circ} \mathrm{C}$, and ignite at $450-$ $500^{\circ} \mathrm{C}$.

13. Dissolve the ash with a $\mathrm{few}$ ml of 1-1 $\mathrm{BCl}$, evaporate on a sandbath and ignite at

\section{Remarks}

Phosphate collection of Th, $\mathrm{Ca}, \mathrm{Fe}$, etc. from large quantity of organic material. Separation from alkali metals.

Removal of remaining traces of organic material.

Separation from $\mathrm{Fe}$ and other heavy metals.

carbonate.

Ignition time may be reduced by dissolving the ash, drying and igniting for the second time, 
$\underline{\text { Procedure }}$

$450-500^{\circ} \mathrm{C}$.

14. Dissolve the ash in a minimum of $0.5 \mathrm{~N} \mathrm{HCl}$.

15. Transfer the sample to a resin column. (Dowex $50 \times-8$, 200-400 mesh, 1.4 x 7 cm.)

16. Wash the column with 50 $\mathrm{ml}$ of distilled $\mathrm{H}_{2} \mathrm{O}$, then $50 \mathrm{ml}$ of $3 \mathrm{~N} \mathrm{HCl}$ at a flow rate of 2 $\mathrm{m} \mathrm{I}$ per minute.

17. Elute with $50 \mathrm{ml}$ of $4 \mathrm{M}$ $\mathrm{H}_{2} \mathrm{SO}_{4}$. Collect in a $50 \mathrm{~m} \mathrm{I}$ volumetric flask.

18. Transfer the solution to a platinum crucible and evaporate the sulfuric acid fraction to near dryness (one or two drops). Cool.

19. Add $2.0 \mathrm{mg}$ of La carrier. Then transfer with distilled $\mathrm{H}_{2} \mathrm{O}$ to a $40 \mathrm{ml}$ centrifuge tube.

20. Dilute to approximately $30 \mathrm{~m} \mathrm{I}$ with distilled H20. Precipitate lanthanum and thorium hydroxides with $\mathbb{M} \mathrm{NaOH}$.

21. Digest the precipitate at $95^{\circ} \mathrm{C}$, then cool to room temperature. Centrifuge for 10 minutes.

22. Decant and discard the supernatant. Dissolve the precipitate with $\mathbf{3}$ or 4 drops of concentrated $\mathrm{HClO}_{4}$ and wash down the sides of the c-tube using minimum of distilled $\mathrm{H}_{2} \mathrm{O}$ (less than $5 \mathrm{ml}$ ).

23. Transfer to a $25 \mathrm{ml}$ volumetric flask with $5 \mathbf{~ m l}$ of $\mathrm{d}$ istilled $\mathrm{H}_{2} \mathrm{O}$.

24. Proceed as outlined under Colorimetric Procedure Chrome Azurol S. $\underline{\text { Remarks }}$

Removal of traces of $\mathrm{Ca}, \mathrm{Fe}$.

Traces of Al may be removed from glassware and interfere with final color determination.

La used as carrier for Thorium.

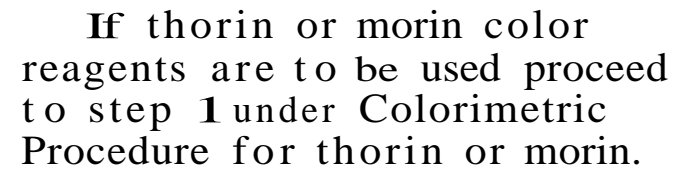

If thorin or morin color to step 1 under Colorimetric Procedure for thorin or morin. 


\section{$\underline{\text { Colorimetric Procedure }}$}

Chrome Azurol S

1. Add 2 drops of $1 \%$ p-nitrophenol.

2. Add 5 normal NaOH until the yellow color just appears.

3. Add 1 normal BClO 4 until the yellow color disappears permanently.

4. Add 1 drop of concentrated $\mathrm{BC}_{104}$.

5. Add $1 \mathrm{ml}$ of a $10 \%$ solution of $\mathrm{NH}_{2} \mathrm{OH}-\mathrm{HCl}$. Heat until solution just begins to boil.

6. Cool slightly and add 10 ll of the buffer solution. Stir well.

7. Add $1 \mathrm{~m} \mathrm{I}$ of Chrome Azurol S dye, and stir. Adjust volume to $25 \mathrm{~m} \mathrm{I}$ with $\mathrm{B} \geq 0$ and stir.

8. Allow sample to stand for 10 minutes, measure the absorbance at 610 mu using a Model DU Beckman Spectrophotometer.

\section{Thorin}

1. Add 10 drops of concentrated hydrochloric acid to the lanthanum hydroxide precipitate from step No. 22 in the Isolation Procedure.

2. Transfer the solution to a $\mathbf{2 5} \mathbf{~ m l}$ volumetric flask. Dilute the sample with approximately 10-15 ml of distilled water.

3. Add $2 \mathrm{ml}$ of $10 \%$ hydroxylamine hydrochloride, then $1 \mathrm{ml}$ of $0,1 \%$ thorin solution.

4. Measure the absorbance at $545 \mathrm{mu}$ using a Model DU Beckman Spectrophotometer. 
Morin

1. Add $1 \mathrm{ml}$ of perchloric acid $\mathrm{pH} 1.0$ to the lanthanum hydroxide precipitate from step No. 22 in the Isolation Procedure.

2. Add $10 \mathrm{ml}$ of perchloric acid $\mathrm{p} \mathbb{Z}$ 2.0.

3. Heat centrifuge tube at $85-90^{\circ} \mathrm{C}$ until precipitate is dissolved. Cool solution to room temperature.

4. Add 1 ml of $10 \%$ hydroxylamine hydrochloride. (Perchloric acid, pस 2.0, is used as solvent.)

5. Add 1 ml of morin solution, then transfer solution to a $25 \mathrm{~m}$ volumetric flask and dilute to volume with perchloric acid o ㅍ 2.0.

6. Measure the absorbance at 410 mu using a Model DU Becken spectrophotometer.

\section{Bibliography}

1. Welford, George A. Industrial Hygiene Association Meeting, April 24, 1958. To be published in the American Industrial Hygiene Association Journal. 


\section{Method B -- Thorium Assay" of Urine}

$\underline{\text { Procedure }}$

1. To a $500 \mathrm{ml}$ urine sample in a 1000 ml Erlenmeyer Flask add $1 \mathrm{~m} \mathrm{l}$ of lanthanum nitrate solution (10 of lanthanum) and $50 \mathrm{~m} \mathrm{I}$ of concentrated nitric acid and evaporate to dryness.

2. Add $10 \mathrm{~m} \mathrm{I}$ of concentrated nitric acid and evaporate. Repeat this step until only white salts remain.

3. Dissolve the salts in 60 $\mathrm{m} I$ of $2 \mathrm{~N}$ nitric acid, and add $1 \mathrm{M}$ of lanthanum nitrate solution, and stir thoroughly.

4. Transfer flask contents to a $100 \mathrm{ml}$ Lusteroid centrifuge tube. Wash the flask with three $10 \mathrm{~m} \mathrm{I}$ portions of $2 \mathbb{N}$ nitric acid, adding washings to the c-tube.

5. Add $5 \mathrm{ml}$ of concentrated hydrofluoric acid, stir thoroughly, and allow to stand one hour.

6. Centrifuge at 1600 r.p. I. for $2 \mathrm{~min}$. Decant the solution, taking care to leave the precipitate untisturbed and dissolve the precipitate in 10 to $20 \mathrm{~m} \mathrm{I}$ of $2 \pi$ nitric acid directed in a fine stream from a wash bottle; dilute to 80 to $90 \mathrm{~m}$ l with $2 \mathrm{~N}$ nitric acid.

7. Add 5 thl of concentrated hydrofluoric acid, stir and allow to stand for 5 minutes. Centrifuge at $1600 \mathrm{r}, \mathrm{p} . \mathrm{m}$. for 2 minutes.

8. Decant the solution and transfer the precipitate to a 45 m I Vycor evaporating dish with the aid of $10 \mathrm{to} 15 \mathrm{ml}$ of $2 \mathrm{~N}$ nitric acid.

9. Add $3 \mathrm{ml}$ of concentrated perchloric acid and evaporate to dryness on a hot plate.

10. Dissolve the residue in
Remarks

1 and 2 are steps to destroy the organic material.
Lanthanum fluoride carrier precipitation of Thorium. Major separation from most elements, rare earth, yttrium and uranium contaminate this precipitate.
Double precipitation of fluorides.
Removal of traces of organic material. 
$\underline{\text { Procedure }}$

$3 \mathrm{ml}$ of $\mathrm{IN}$ nitric acid and transfer the solution to a separatory funnel containing $10 \mathrm{ml}$ of $0.45 \mathrm{M} \mathrm{2-thenoyltri-}$ fluoro-acetone in benzene,

11, Wash the Vycor dish with three $1 \mathrm{ml}$ portions of water, adding the washes to the separatory funnel. Shake for 5 minutes at maximum agitation on a mechanical shaker, then add $10 \mathrm{ml}$ of distilled water and shake for 15 minutes. Discard the aqueous layer. Wash the inside of the separatory funnel with 25 to $35 \mathrm{ml}$ of distilled water by spraying from a wash bottle, then discard the wash water.

12. Wash the 2-thenoyltrifluomacetone-benzene layer by shaking it with three $5 \mathrm{~m} \mathrm{I}$ portions of 0.2 I? nitric acid 5 minutes each, discarding the aqueous layer each time. Wash the inside of the separatory funnel with 25 to $35 \mathrm{ml}$ of distilled water by spraying from a wash bottle and discard the wash water.

13. Add $10 \mathrm{ml}$ of $2 \mathrm{~N}$ nitric acid and shake 15 minutes.

14. Let stand for $30 \mathrm{~min}$. to allow complete separation of the phases.

15. Withdraw the aqueous phase into a $45 \mathrm{ml}$ Vycor dish containing $3 \mathrm{ml}$ of concentrated perchloric acid。

16. Place the samples on an asbestos-covered hot plate and cover them with an inverted rectangular borosilicate glass dish. (To allow the fumes to escape while preventing entrance

\section{Remarks}

Thorium separation from lanthanum, yttrium and uranium. Po chief contaminant.
Thorium stripped from organic phase and separated from Polonium.

Incomplete separation here may lead to a milk explosion and the loss of the sample during the next steps. Removal of trace organic material . 


\section{Procedure}

of dust from the hood ventilating air,)

17. Evaporate to dryness.

Remove the dishes from the hot plate and allow them to cool.

18. Add $3.3 \mathrm{ml}$ of perchloric acid at $\mathrm{pH} 2.0$, swirl 0.5 minute, allow to stand 5 minutes, and s w ir 1 again.

19. Transfer $3.0 \mathrm{ml}$ of the sample to the spectrophotometer cell and add $0.50 \mathrm{ml}$ of morin solution,

20. Prepare a blank solution containing $3.0 \mathrm{ml}$ of perchloric acid at pH 2 and $0.50 \mathrm{ml}$ of morin solution.

21. Place the cap on the cells and invert several times to mix.

22. Allow to stand $\mathbf{1}$ hour and measure the absorbance at a wave length of $412 \mathrm{mu}$ and a slit width of $0.03 \mathrm{~mm}$ on a Beckman Model DU spectrophotometer. $\underline{\text { Remarks }}$

Thorium is absorbed on container walls in solutions with pH greater than 3.0 .

\section{Bibliography}

1. Perkins, R.W. and Kalkwart, D.R. Anal. Chem. 28, 1989, December, 1956。 


\author{
Recommended Procedures for Tritium \\ Reviewer -- Julian M. Nielson \\ August, 1958
}

\title{
EVALUATION OF EXISTING METHODS AND SENSITIVITY
}

The determination of tritium in urine samples is mainly a problem of weak beta activity measurement, since only very simple procedures are required to obtain the tritium in a form suitable for the radioactivity measurement. Seven procedures for tritium bioassay were submitted which could be divided into three groups on the basis of the type of measuring instrument used. These three types of instruments are the vibrating reed electrometer used by the Mound Laboratory, the Y-12 Plant of the Union Carbide Nuclear Company, and the Savannah River Plant; the internal G. M. Counter used by Argonne National Laboratory, Hanford Atomic Products Operation, and Los Alamos Scientific Laboratory; and the liquid scintillation counter used by the University of California Radiation Laboratory. In general, most sites used a vibrating reed electrometer method for their initial work, followed later in some cases by a change to internal G. M. or liquid scintillation counting as a result of the greater suitability of the last two mentioned instruments for handling a large number of samples with a high sensitivity. Since submission of the procedures, Hanford has adopted liquid scintillation counting and the Savannah River Plant has obtained a liquid scintillation counter with an automatic sample changer which they are evaluating for suitability in routine tritium bioassay. Even with these changes, use of the three types of instruments is quite evenly divided.

Comparison of the three types of procedures shows that results obtained are quite similarly suitable and satisfactory for bioassay work, with the choice of instrument mainly dependent on the requirements and conditions of the particular laboratory. Some of these factors are considered below.

\section{Sensitivity.}

Each of the three instruments can successfully detect concentrations of tritium as low as $1 \mathrm{\mu c} / \mathrm{liter}$. Assuming a body burden li mit. of $3700 \mathrm{Hc}$ in the body water, as suggested by E. H. Pinson and W. H. Langham (J. Applied Physiology 10, 108 (1957)) and using the latest recommendations of the NCRP (Industrial Hygiene Quarterly 18, 73 (1957)) of 43.4 liters as the body water content of a standard man and a factor of three to correct to gonad exposure, the value of tritium in the urine corresponding to an MPC is calculated to be $28 \mu \mathrm{c} / 1$. Thus, a detection 1 imit of $1 \mu_{c} / 1$ iter would represent about three percent of the MPC. 
Sample Preparation,

The sample preparation techniques for the procedures using the vibrating reed electrometer and the G. M. counter are similar and involve the generation of hydrogen (and tritium) gas from the urine. This is usually accomplished on calcium or zinc turnings. The use of calcium is simpler and shorter since the metal bed need not be heated as is the case with zinc. However, the specific activity of the gas obtained by the calcium method is only about 70 percent of that from the zinc method. The sample preparation step requires only a $\mathrm{few}$ minutes if the calcium reaction is used, while the zinc method probably could not be done in less than 30 minutes,

The sample preparation technique for the liquid scintillation counter involves the distillation of a few milliliters of the urine. This is sometimes preceded by a decolorization step which prevents excessive foaming during the distillation. The pure water is used directly in the liquid scintillation medium.

\section{Sample Counting。}

For comparison purposes, if it is assumed that the procedure is set up to determine one-tenth MPC $(2.8 \mu \mathrm{c} /$ liter urine $)$ with a standard deviation of ten percent due to counting statistics, the counting times may be calculated for typical instruments.

\begin{tabular}{|c|c|c|c|}
\hline Instrument & $\begin{array}{l}\text { Sample Count Per } \\
2.8 \mu \mathrm{c} / 1 \mathrm{H}_{2} \mathrm{O}^{*}\end{array}$ & Bkg. $(\mathrm{c} / \mathrm{m})^{*}$ & $\begin{array}{c}\text { Counting Time Sample } \\
+ \text { Bkg. To Get Standard } \\
\text { Deviation of } 10 \text { Percent } \\
\text { (Minutes) }\end{array}$ \\
\hline Vibrating reed & $1.5 \times 10^{-16} \mathrm{Amp}$ & $6 \times 10^{-16} \mathrm{Amp}$ & 6 \\
\hline $\begin{array}{l}\text { Internal G.M. } \\
\text { (Hanford type) }\end{array}$ & $50 \mathrm{c} / \mathrm{m}$ & 25 & 5 \\
\hline $\begin{array}{l}\text { Internal G.M. } \\
\text { (Los Alamos type) }\end{array}$ & $95 \mathrm{c} / \mathrm{m}$ & 350 & 9 \\
\hline Liquid Scintillation & $200 \mathrm{c} / \mathrm{m}$ & 450 & 3 \\
\hline \multicolumn{4}{|c|}{ Data for vibrating reed given as current. } \\
\hline \multicolumn{4}{|c|}{$\begin{array}{l}\text { For these calculations it was assumed that the vibrating reed has } \\
\text { a, } 250 \mathrm{ml} \text { chamber and that the calcium-water reaction was used for it } \\
\text { and for the internal G. M。 counters. For the liquid scintillation } \\
\text { counter one ml of water was added to } 65 \text { m I liquid scintillator solution. } \\
\text { It was also assumed that a background would be taken with each sample. }\end{array}$} \\
\hline
\end{tabular}


This is generally not necessary and fewer, longer backgrounds might be used with attendant reduction in overall counting times needed, These times include background and sample counting times, but do not represent true total times necessary to complete one counting operation. After filling and mounting the ionization chamber on the electrometer, a preliminary period of up to 20 minutes depending upon sensitivity desired may be necessary before stable operation is assured. With the internal G. $M_{0}$ c counters, an operating voltage must be determined to make certain that counting is performed on the voltage plateau. This is generally done by determining the starting voltage using an external source and then setting the operating voltage relative to the starting voltage. The liquid scintillation sample generally must be cooled to a temperature near zero centigrade and must be isolated from light for a brief period before counting, In this latter case, however, this cooling and dark adaptation may take place while other samples are being counted and thus do not restrict use of the instrument.

From the considerations above, and for determinations of high sensitivity, the liquid scintillation counter proves to be capable of handling the greater number of samples, while the vibrating reed electrometer handles the fewest.

$+\mathrm{C}$

Equipment for each of the three types of procedures can be obtained for as low as $\$ 3,000$ to $\$ 4,500$, with the liquid scintillation apparatus the most expensive, Automatic sample changing is possible with the liquid scintillation counter and such an instrument with a capacity of 100 samples can be obtained for about $\$ 16,000$. No comparison of the costs per sample, except for liquid scintillation samples for which the chemical costs about $\$ 0.50$ per sample, On the subject of cost, it is interesting to note that one cumercial firm (Tracerlab, Inc., Waltham 54 , Massachusetts) offers tritium urinanalysis at $\$ 10$ per sample for single samples and $\$ 5$ per sample on a contract basis.

\section{Equipment Maintenance.}

Perhaps the most important factor in choosing an instrument for tritium bioassay is the instrument experience of the personnel who will operate and maintain the instrument. In laboratories where other operations involve the use of either ion chambers, internal G。 $M$ 。 counters, or scintillation counters, that instrument may be the best choice for the tritium work, Experience with these types of instruments for tritium bioassay have varied widely. For instance, one site was able to analyze routinely only about seven samples per day per vibrating reed electrometer (in this case acetylene wenerated as the counting gas and a one-liter chamber used) while another site has 
been able to do about 25 samples per day per vibrating reed electrometer. Several factors operated here but the difference is largely due to maintenance troubles. Many sites reported difficulty in maintaining the external quench used with internal G.M. counting while one site routinely used this instrument to determine as high as 50 samples per day per instrument. External quench problems are eliminated if the Los Alamos type internal G。 M. counter is used. The liquid scintillation counter is the most electronically complex of the three instruments, but many sites now have scintillation counters of various types and pulse height analyzers and thus, are familiar with the type of maintenance involved with this type of counting instrument.

The three types of tritium bioassay methods reviewed above (ion chamber, 1nternal G.M.counter, and liquid scintillation counter) are capable of satisfactory and comparable results. The method of choice depends upon many conditions including the number of samples to be run and the training and experience of the personnel who will operate and meintain the instruments. If only a few samples per day are to be analyzed, each method is suitable. For large numbers of samples the vibrating reed electrometer method becomes less desirable, but satisfactory. If automatic sample changing and counting are desired, the liquid scintillation counter is to be preferred, All other factors equal the liquid scintillation counter method has the advantage in sample preparation of simple, safe operation, requiring no vacuum work or hydrogen generation.

Typical stepwise procedures for the various measuring instruments are given below as examples:

\section{Vibrating Reed Electrometer.}

See attached procedure from the Savannah River Plant.

Externally Quenched G。M。

Radiation Research 4, 278 (1956). Hydrogen Counter for Analysis of Dilute Tritium Oxide, J.W. Healy and L。C.Schwendiman, and attached stepwise procedure from Banford.

\section{Internally Quenched G。M。Counter,}

LA-1858. Analytical Procedures of the Industrial Hygiene Group, December 1954, Chapter 26, The Determination of Tritium in Urine and Water. Pg。140-154。 (Editor's note: This method is not reproduced here because it is available in the AEC literature and because it incorporates abundant detail and illustrations making it difficult to dupdieate.) 


\section{Liquid Scintillation Counter,}

Approximately $25 \mathrm{ml}$ of urine and $\mathbf{1}$ gram of activated charcoal are mixed in a $50 \mathrm{ml}$ beaker, After standing for 20 - 30 minutes, the urine is filtered. A water sample is distilled from the decolorized urine utilizing the simple distillation set-up illustrated, (Fig. I.) If the decolorizing step is omitted, foaming during the distillation becomes a problem.

A $0.5 \mathrm{ml}$ sample of the urine distillate is added to $65 \mathrm{ml}$ of the scintillation mixture." A standard and background sauple are prepared each day. The samples are assayed in a coincidence-corrected liquid scintillation counter. The decolorization and distillation steps effectively remove all quenching problems.

A resampling procedure should be set up using a li mit based upon the bioassay $1 \mathrm{im}$ it accepted by the site concerned, In order to properly integrate exposure, tables siach as given in LA-2163 (Estimation of Whole Body Dose (Rem) From Tritium in Body Water) are helpful.

\section{Automatic Sample Changer Scintillation Counter.}

DPSOP - 38, July 1958. Mr。C.M.Patterson of the Savannah River Plant has sent the reviewer the new Savannah River tritium procedure (see attached copy) using an automatic sample changer liquid scintillation counter. As presently used the urine tritium content can be measured to the nearest microcurie per liter with a one minute count. In order to assess the quenching effect (and, hence, counting efficiency) of the urine sample, a second count is taken after addition of a known amount of tritium. The cost of scintillation mixture per sample is about $\$ 0.12$ per sample and polyethylene vials, which cost $\$ 0.03$ each, are used once only.

The scintillation mixture consists of::

23 vol. percent absolute alcohol

77 vol. percent toluene

4 gm. diphenyloxazole

15 diphenylhexatriene. 
TRITIUM URINALYSIS USING A VIBRATING REYD EIECTROMETER

The tritium analysis consists of generating hydrogen by the decomposition of water in urine and introducing it into an evacuated oneliter ionization chamber (Applied Physics Corporation Model No. 3095C). The ionization current produced by the radiation is then measured across a $10^{12}$-ohm Hi-Meg resistor (Victoreen Instrument Company) on an Applied Physics Corporation Vibrating Reed Electrometer Model 30. The readings are recorded on an Esterline-Angus Model AW DC milliammeter. The detailed procedures are as follows:

1. Assemble the apparatus including an acetylization flask, a 20-ml burette, a U-shape condenser, a drying tube and a manifold as shown in the attached drawing.

2. Connect the one-liter ionization chamber, the vacuum valve on the bench top*, and a vacuum gauge to the manifold with $1 / 4^{\prime \prime}$ x 3/16" pressure-vacuum tubing。

3. Place a small amount of glass wool in the bottom of the drying tube, Add enough 6-16 mesh Tell Tale Silica Gel (Fisher Scientific Company) to fill the drying tube to within 1.5 inches of the top. (Both molecular sieves produced by Linde Company, a division of Union Carbide Corporation, and a combination of indicating Drierite and Anhydrous calcium chloride have also been used in the drying tube。)

4. Place a wad of glass wool in the top of the drying tube leaving enough room for the ground glass joint of the condenser to fit in.

5. Add about 3 of metallic calcium to the acetylizstion flask.

6. Turn the 3-way stopcock of the manifold so that a 113 side arms are open。

7. Evacuate the apparatus by opening the vacuum valve on the bench top and turning on the Cenco-Megavac vacuum pump beneath the bench.

8. When the vacuum gauge stops dropping, turn the 3-way stopcock $1 / 4$ turn clockwise or until the vacuum side-arm is closed. Stop the vacuum pump and release the vacuum by removing the stopcock plug from the vacuum valve on the bench top.

9. Add about $20 \mathrm{ml}$ of the urine to be analyzed to the burette.

* A vacuum supplied by Cenco-Magavac pumps is available through stopcock type valves on the bench top in the Savannah River Plant Bio-Assay Laboratory。 
10. Check the apparatus for leaks by noting if the reading of the vacuum gauge has changed.

11. Crack the stopcock on the $20 \mathrm{ml}$ burette and allow the urine to enter the acetylization flask dropwise, (Care must be taken not to generate the hydrogen too rapidly or the heat of the reaction will boil the excess water over into the drying agent and ionization chamber. The acetylization flask may be placed in the beaker of water to remove the heat of reaction.)

12. When the pressure in the apparatus has again reached atmospheric pressure, turn the 3-way stopcock $1 / 4$ turn clockwise or until the side am to the ionization chamber is closed, and measure the ionization current on a vibrating reed electrometer.

\section{OPERATION OF THE VIBRATING REED ELECTROMETER AND GRAPHIC MILIIAIMETER}

1. Close the shorting switch on the electrometer head (above the connector jack) by turning it $1 / 2$ turn in either direction.

2. Place the zero adjuster switch in the positive $(\rightarrow)$ position.

3. Place the meter switch in the center position.

4. Place the range switch in the 1000-millivolt position.

5. Turn the power switch on and allow sufficient time for the instrument to warm up. (A warm-up period of several hours is required, and it is preferable to leave the electrometer on continuously.)

6. Connect the negative (-) conductor of a $221 / 2$-volt battery to the chamber and the positive $(\not)$ ) conductor to the electrometer head.

7. After sufficient time has been allowed for warm-up, start the Graphic Milliammeter by turning the power switch on. (The drive on the Graphic Milizmeter should be set so that the chart moves at a rate of 6 inches per hour.)

8. Place the meter switch in the negative (-) position and zero the meter by turning the zero adjustment until the milliammeter reads zero. (The shorting switch must be closed and the meter re-zeroed each time the range switch position is changed.)

9. Fill the chamber with non-radioactive hydrogen. This can be done by using an aqueous solution of calcium chloride and the above urinalysis procedure, 
10. Take a background reading by turning the shorting switch knob on the electrometer head $1 / 2$ revolution in either direction and noting the reading on the chart. If the reading does not lie between 1 and 10 on the scale, change the position of the range switch and repeat steps 1,8 , and 10 .

11. Fill the chamber with the hydrogen genersted from the sample, and repeat steps 1 and 8 , open the shorting switch, and note the reading on the Graphic Milliammeter. Readings on the chart are made by allowing the Graphic Milliammeter to run for a period of 15 minutes. During this time the pen will indicate a number of minimum readings, These minimum readings less background readings are compared with similar readings of samples of known concentrations of tritium in $\mu \mathrm{c} / \mathrm{l}$.

The detection limit of this procedure is $\mathbf{1}$ Hc of tritium per liter of urine.

Urine samples are collected on the plant for tritium analysis from those persons working in areas where assimilation is possible. In certain areas single voids are collected daily from each employee near the and of each shift. 'In others, urine voidings are collected only when the stuation dictates.

The method of relating bio-assay results to concentration of tritium in the body is based on the assumption that the body contains 50 liters of water and this water is in equilibrium with the urine. The amount of tritium in the body is therefore determined by multiplying the concentration in urine in $\mu \mathrm{c} / 1$ by 50 . If cases of particular interest occur, the employees weight and biological half-life are used to more accurately estimate the absorbed dose received.

An employee is removed from the work area when the concentration of tritium in his urine exceeds $20 \mu_{c} / 1$ and is not allowed to return until it drops below $10 \mathrm{\mu c} / 1$. 


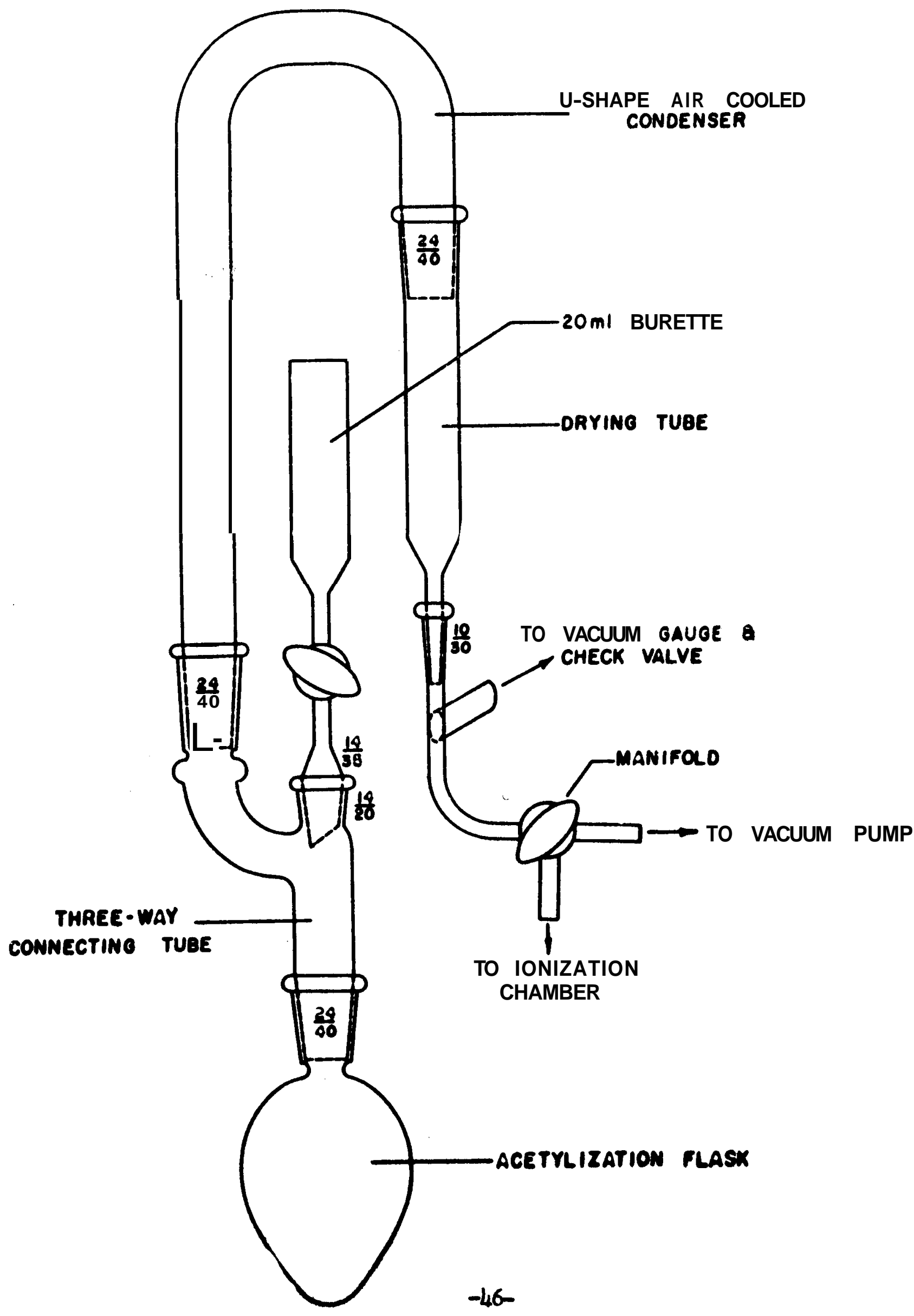




\section{DETERMINATION OF TRITIUM I N URINE AND OTHER \\ LIQUID SAMPLBS USING AN EXITERNAIIYY \\ QUENCHED G.M.COUNTER}

\section{Purpose:}

The hydrogen counter is used to measure the amount of activity due to tritium oxide in liquid samples, chiefly wine and moisture collected from the air. This is accomplished by reacting the liquid with calcium metal to release hydrogen and tritium from the water present. This hydrogen, and tritium, which is radioactive, is used to fill a Gieger tube and the activity present is measured.

\section{Equipment:}

The parts of the equipment are:

1. Counting chamber: This is a lead pig within which are mounted on the longitudal axis two thin walled glass Gieger tubes. The filling tube of each is connected to the filling equipment with Tygon tubing. Centrally located between the two tubes is a holder to maintain a gamma source in a reproducible position.

2, A selector switch to connect the high voltage with whichever tube is to be counted.

3. A quench circuit to limit the pulse produced in each tube.

4. High voltage supply.

5. A conventional scale of 64 scaler.

6. Filjing manifold: This is connected to a vacuum pump through a valve and through tubing to the filling equipment and a manometer. On the manifold are three valves, one of which is connected to each of the tubes and the third one opens into the air to serve as a relief valve.

7. The manometer is used to indicate the degree of pressure in the GM tubes and to detect any leaks that might occur.

8. Filling unit: This consists of:

a. A 60 mil round bottom flask with a joint at the neck and a side arm with a Joint.

b. A small dropping funnel which fits into the side arm.

c. An L-shaped air condensor that fits into the neck of the flask. 
d. A dryi $\&$ tube that onnect the upper end of the air condensor with the manifold. The drying tube is, filled with magnesium perchlorate except for the end nearest the manifold which contains about an inch of indicating Drierite.

\section{Counting Procedure:}

The scaler and power supply turned on previously and in operating condition.

1. Place in flask 2 - 3 grams of metallic calcium turnings and 1 - 2 grams of anhydrous calcium chloride. Shake flask to mix.

2. Wipe off any particles that adhere to inside of neck of flask and grease neck lightly with stopcock grease.

3. Insert end of condenser into neck of flask and insert its other end, previously greased, into end of drying tube.

4. Clamp neck of flask onto ring stand.

5. Grease funnel lightly with stopcock grease and insert into side opening of flask.

6. Start vacuum pump, open stopcock to GM tube, close relief valve and allow system to become evacuated as shown by manometer reading.

7. Close vacuum line valve and observe manometer. If mercury falls, check for leaks. Continue to check until no leaks are apparent.

8. Open vacuum line valve and re-evacuate the system.

9. Close vacuum line valve.

10. Pour sample into funnel.

11. Turn stopcock on funnel rapidly to allow small amount of sample to run onto calcium metal. Allow enough sample to enter in to the flask to fill the GN tube slowly as indicated by the dropping of mercury in the manometer.

12. Open relief valve and close tube valve rapidly, in that order, ss soon as the tube is filled and bubbling occurs in the manometer reservoir.

13. Place gamma source in holder in pig.,

14. Turn selector switch to proper tube.

15. Turn counting switch to "count" position. 
16. Turn high voltage up slowly until the lights begin to flash.

17. Turn the voltage back down until the lights just stop flashing.

18. Raise high voltage enough to get it into the center of the plateau as determined by plateau measurement $(100-150$ volts $)$.

19. Remove source from holder in pig.

20. Turn counting switch to "stag."

21. Reset lights, register, and clock to zero.

22. Turn counting switch to "count".

23. Count for five minutes.

24. Turn high voltage down to zero and tube selector switch to neutral.

25. Record number registers, lights, and time of count.

IV. Computation of Results:

1. Multiply number of registers by scale of 64 .

2. Add to this figure the number of interpolation lights.

3. Divide above sum by length of count in minutes.

4. Subtract blank c/m.

5. Divide net c/m by "tube factor" and result is uc/Iiter.

V. Control Procedures for Tr $\quad l$

Controls are necessary for two reasons:

1. To determine operating characteristics of a new tube. basis.

2. To determine if the set is operating properly on a day to day

Whenever a new tube is installed, three things must be determined about it :

1. Background value of tube,

2. Tube voltage plateau. This is necessary to determine the number 
of volts above the threshold that the high voltage should be set in order that the tube will give reproducible results on successive runs.

3. The "tube factor". This is a figure that relates the number of counts per minute of a sample to the activity of the sample in uc/liter.

\section{A. Background Measurements}

Blanks are run by following the counting procedure as outlined but using distilled water as a sample.

B. Geometry Measurements-Spike Controls

Spikes are run by following counting procedure as outlined in Section III using a spike, or solution with known activity density due to tritium as a sample.

\section{C. $\quad$ Plateau Measurement}

1. - 10, Repeat counting procedure in Section III to step 10, using distilled water for a sample.

11. Insert source into pig.

12. Turn selector switch to tube to be checked.

13. Set counting switch to "count".

14. Turn high volage up until lights begin to flash.

15. Set counting switch to "stop".

16. Reset lights, register and clock to zero.

17. Count for one minute and record count and voltage.

18. Advance voltage 50 volts and repeat one minute count and record.

19. Make series of one minute counts advancing voltage 50 volts each time. Continue until counting rate changes markedly. Warning: Reduce voltage to previous reading if counting ratebecomes very rapid.

20. Plot counting rate vs. voltage on linear graph paper. Operate instrument in middle of plateau.

D. Determination of Tube Factor

1. Follow counting procedure outlined in Section III, Steps 1-10. 
2. Pour into funnel a standard sample spike with activity density of approximately $20 \mathrm{uc} / 11 \mathrm{ter}$. III.

3. Proceed with Steps 11 through 25 of counting procedure Section

4. Repeat steps $\mathbf{1}$ through $\mathbf{3}$ twice.

5. Repeat Steps 1 through 4 using a spike with activity density of approximately 30 uc/Iiter.

6. Repeat Steps 1 through 4 using a spike with activity density of approximately $50 \mathrm{uc} /$ liter. rate.

7. Subtract blank from each gross count to obtain net counting

8. Average the net $\mathrm{c} / \mathrm{m}$ for each spike level.

9. Divide each average $\mathrm{c} / \mathrm{m}$ for each spike level by spike activity density in uc/liter. The results should be approximately the same for each spike level used.

10. Average the three results obtained in Step 9. This average is the tube factor.

\section{E. Control Charts}

Control charts are established on both spikes and blanks to ascertain if equipment is in operating control on a day-to-day basis. Limits must be established for each tube.

1. Blank Control Charts

a. Run a series of 10 blanks (See Section V-A).

b. Find average $c / m$.

c. Find average of total counts.

d. Compute confidence limits using following equations:

$$
\mathbf{E}=\frac{\mathrm{K} \quad \mathrm{N}}{\mathrm{t}}
$$

Where: $\mathbf{E}$ is the deviation in counts per unit time $\mathrm{K}$ is the confidence $\mathbf{N}$ is the average of total counts factor: 
(Step b) •

e. Add and subtract results from Step (d) to average $\mathrm{c} / \mathrm{m}$

f. Plot $\mathrm{c} / \mathrm{m}$ on vertical axis of linear graph paper so that average $\mathrm{c} / \mathrm{m}$ will fall in middle of graph.

g. Construct lines across the chart at each value obtained from Step (e).

h. (1) If first point falls within $95461 \mathrm{imits}$ of control chart, set is in proper operation.

(2) If first point falls within 99\% limits and second falls within $95 \%$ limits, set may be used.

(3) If first point falls outside $99 \%$ limits, the next two points must fall inside limits.

(4) If two successive points fall outside $95 \%$ limits, equipment should be recalibrated.

\section{2. $\quad$ Spike Control Charts}

a. Multiply tube factor found in Section V-D by spike value and by 5 to get total number of counts in a five minute period.

b. Compute 1 im its by equation, Part I, Section V-E, Step (d). liter.

c. Divide limits from (b) by tube factor to convert to uc/

d. Add and subtract limits found in (c) from spike value.

e. Plot uc/liter on vertical axis of linear graph paper using a scale so that the spike value will fall in the middle.

f. Construct lines across the chart at each value determined in $\operatorname{Step}(\mathrm{d})$.

g. Operational tests are same as for blank (Part h). 
DETERMINATION OF, TRITIUM IN URINE AND WATER SAMPLES

BY USE OF AN AUTOMATIC SAMPLE CHANGER AND

LIQUID SCINTILLATION COUNTER

$\underline{\text { Principle, Limitations, and Precision }}$

This method was developed for assaying urine and water samples for tritum content, and uses the Packard Tri-Carb Liquid Scintillation Spectrometer, Model 314. Suitable volumes of samples are added to scintillation solution and allowed to cool at $4^{\circ} \mathrm{C}$ in the Tri-Carb freezer, while at the same time re-emitting any light absorbed in the counting vial. When equilibrium conditions are attained, a maximum load of 100 samples may be counted by using the automatic changer. For samples, such as urine, with varying amounts of quench due to colored compounds, the original solution may be internally spiked with a known amount of tritium. After recounting the sample, the quench factor may be calculated and applied to the original count for an accurate analysis.

The Packard instrument counts light emissions resulting from impacts of the weak Beta particles on the ingredients of the scintillation mixture. The counter is designed for maximum sample sensitivity while screening out cosmic and other activity along with thermionic emissions. The discrimination setting of the counter is adjusted to exclude counts of all activity in urine with energy greater than that of tritium.

Weter samples may be counted to a sensitivity of less than .01 uc GTO/1 with a 30 minute count. Greater sensitivity may be obtained with longer counts. Urine samples are counted to a sensitivity of $1 \mathrm{uc}$ BTO/I with a one minute initial count. At the $99 \%$ confidence level, urine samples which count less than $150 \mathrm{c} / \mathrm{m}$ contain less than $1 \mathrm{uc}$ imo $/ 1$.

\section{Equipment}

Packard Tri-Carb Scintillation Spectrometer, Model 314, with freezer and automatic changer.

One-half ounce polyethylene "Boston Round" vials obtained from the H- Smith Company.

Automatic $50 \mathrm{ml}$ dispensing burette.

Microburette with 2 ml capacity.

One ml volumetric pipettes.

Three ml volumetric pitettes. 


\section{$\underline{\text { Reagents }}$}

P-dioxane, M.P. $10.5-11^{\circ} \mathrm{C}$, obtained from Eastman Organic Chemicals.

Naphthalene, recrystalized from alcohol, obtained from Eastman Organic Chemicals.

2,5-diphenyloxazol (PPO), scintillation grade, obtained from Pilot Chemicals, Inc.

p-Bis-2-(5-phenyloxazolyl) - benzene (POPOP), scintillation grade obtained from Pilot Chemicals, Inc.

Tritium oxide spike about $0.7 \mu \mathrm{cro} / \mathrm{ml}$.

$\underline{\text { Safety }}$

A 11 rules and regulations found in the Safety Manual should be strictly followed. Dioxane is a flammable solvent and should be handled and stored in a solvent hood. Since the toxicity of other scintillation chemicals is not known they should be handled with gloves.

Procedure

Preparation of Scintillation

Mixture

1. Use an analytical balance to weigh $4.000 \mathrm{gm}$ PPO and 0.0500 gm POPOP.

2. Use a laboratory trip balance to weigh $110.0 \mathrm{gm}$ naphthalene.

3. Measure $1000 \mathrm{~m} \mathrm{I} \mathrm{p-dioxane,}$ using a graduated cylinder.

4. Pour the dioxane into a brown bottle and add the PPO, POPOP and naphthalene.

5. Dissolve all solids before use. (Mote 1)

\section{Hazard Breakdown}

1. Use gloves when handling chemicals.

3. Measure the dioxane in a solvent hood. 
Sample Preparation for Water Samples

1. Add 3 ml of each sample to a polyethlene vial using a volumetric pipette.

2. Using an automatic burette, add $12 \mathrm{ml}$ of scintillation mixture to each sample.

2. Perform this work under a hood.

3. Stopper the vial and mix the solution.

4. With each 48 samples prepare one distilled water blank and one tritium spike. (Note 2)

Sample Preparation for Urine Samples

1. Add 1 ml of urine sample to a polyethylene vial, using a volumetric pipette.

2. Using an automatic burette, add $15 \mathrm{ml}$ of scintillation mixture to each sample.

3. Stopper the vial and mix the solution.

4. With each group of 48 samples, 4. An average quench factor prepare one distilled water blank and one tritium spike. (Note 2).

2. Perform this work under a hood. may be used on samples containing $<5$ HC $\mathrm{HMO} / 1$ thus eliminating a spike for these.

Operation of the Tri-Carb Counter

1. Leave the automatic switch turned to "Normal".

2. Turn the operating switch to "Turntable Reset".

3. Set the "Preset Time" switch to the desired time. 
4. Set the "Sample Number" switch for the number of eamples to be counted.

5. Turn the operating switch to "Operate". (Note 3)

Sample Counting for Water Samples

1. Switch off the room lights and place the proper samples in the numbered positions on the numbered positions on the automatic turntable. (Note 4).

2. Set the ripreset Time" switch for 10 minutes and count for the desired time. (Note 5)

3. Remove the samples and add 100 lambda of $0.7 \mu \mathrm{c} \mathrm{BTO} / \mathrm{ml}$ tritium spike to each vial.

4. Replace the vials and count the samples for 0.3 minutes each after equilibrium is re-established.

\section{Sample Counting for Urine Samples}

1. Switch off room lights and place the samples in the numbered positions on the automatic turntable. (Note 4).

2. Set the "Preset Time" switch for one minute and count the samples.

3. Remove each vial and spike a 11 samples which counted $100 \mathrm{c} / \mathrm{m}$ or more with 100 lambda of $0.7 \mathrm{Hc}$ HTO/ml.

4. Replace the sample vials and recount the samples for 0.3 minutes each after equilibrium is re-established. 
Calculation of Tritium Content of Samples

1. A 11 urine samples which originally counted less than $100 \mathrm{c} / \mathrm{m}$ equal less than $1 \mathrm{Hc}$ HTO/1.

2. For samples which were internally spiked (water or urine) calculate $a s$ follows:

$($ sample + spike $) \mathrm{c} / \mathrm{m}-($ sample $) \mathrm{c} / \mathrm{m}=\mathrm{c} / \mathrm{m}$ due to spike

$\frac{c / m \text { due to spike }}{\mu c \text { HTO/I added }}=c / m / \mu_{c} / 1$ due to known spike $\frac{\text { sample } c / m-\text { blank } c / m^{*}}{c / m / H c / 1 \text { due to known spike }}=\mu_{c}$ HTo/1 of sample

* The average blank urine $\mathrm{c} / \mathrm{m}$ is 54 . Distilled water gives $20 \mathrm{c} / \mathrm{m}$.

The calculations above may be simplified by use of a nomograph.

\section{NOTES}

1. In practice, larger amounts of scintillation mixture should be grepared to conform to sample load and solvent storage space. Six batches of mixture may be prepared and dissolved in the original browl dioxane bottles. Allow two days for complete solution of mixture before use. No change in scintillation efficiency has been noted after setting for several months. Each fresh mixture should be checked for efficiency by counting a known spike and recording the result on a table or graph.

2. The spike should be at a level of 10 to 50 Ho Hro/1. It may be used to compare the efficiency of scintillation mixtures, as well as that of the Tri-Carb, for each group of samples.

3. Allow about one minute for the turntable to begin to reset before turning the "Operate" switch. To check for sample equilibrium, the lower left switch may be turned to "Repeat" after beginning of counting of sample No. 1. After a constant count is obtained, the switch may be turned to "Normal" to complete the cycle. Be sure enough printing paper is left to record samples. 
4. The effect of direct fluorescent room lighting on sample vials is harmful and should be avoided whenever practical. Samples should also be protected from light.

5. Water samples are generally those for low level regional survey. A total of $\mathbf{3 0}$ minutes of counting time is used for these samples.

\section{REFERENCES}

1. Operation Manual for the Packard Tri-Carb Liquid Scintillation Spectrometer, Model 314 Packard Instrument Company, Inc., La Grange, Illinois. Butler, F.E., DPSPN 774. 


\author{
Recommended Bio Assay Procedures for Uranium \\ Reviewers - - Mont G. Mason, \\ Richard H. Burr, Jr。 \\ October 1958
}

I. Sample Collection. The sample collection procedure for routine urinary uranium analysis normally involves the collection of a "Monday morning" (a morning following two or more days off the job) or a "Friday afternoon" (a sample taken the last day of the work week at the conclusion of the work day) urine specimum. On particular occasions 24-hour urine specimums may be collected to augment the routine samples or to provide more accurate data for a specific circumstance.

II. Normal Uranium Urinalysis. Methods A and B utilize the fluorescence of ionic uranium intensified by fusion with sodium fluoride or a sodium fluoride-sodium carbonate mixture, to provide the basis for an empirically quantitative method for the determination of "nors uranium in the range $10^{-10}$ to $10^{-5}$ grams or higher. Although these methods are relatively free from interferences, the uranium fluoreacence may be "quenched"' by a number of ions, particularly those of certain heavy metals. However, this quenching is much less marked in the case of pure sodium fluoride than in mixed carbonate fluxes. Consequently the major differences between the two methods presented is that one method considers the quenching effect neglydole, and the other incorporates in the procedure a system to evaluate possible quenching effects. The empirical nature of the fluorimetric method docessitstes the adoption of a procedure with which rigidly reproducible experimental conditions can be maintainea.

A number of sat1sfectory fluorimeters or flingopotometers arc available and can be adopted $t$ o routine use.1,2,3,4,5. Several are available comercially. One such fluorimeter manfoctured by the Jarrell-Ash Company has been developed specifically for uranium ans 1ys 18. Figures 1 and 2 depict one type of fluorophotometer. 


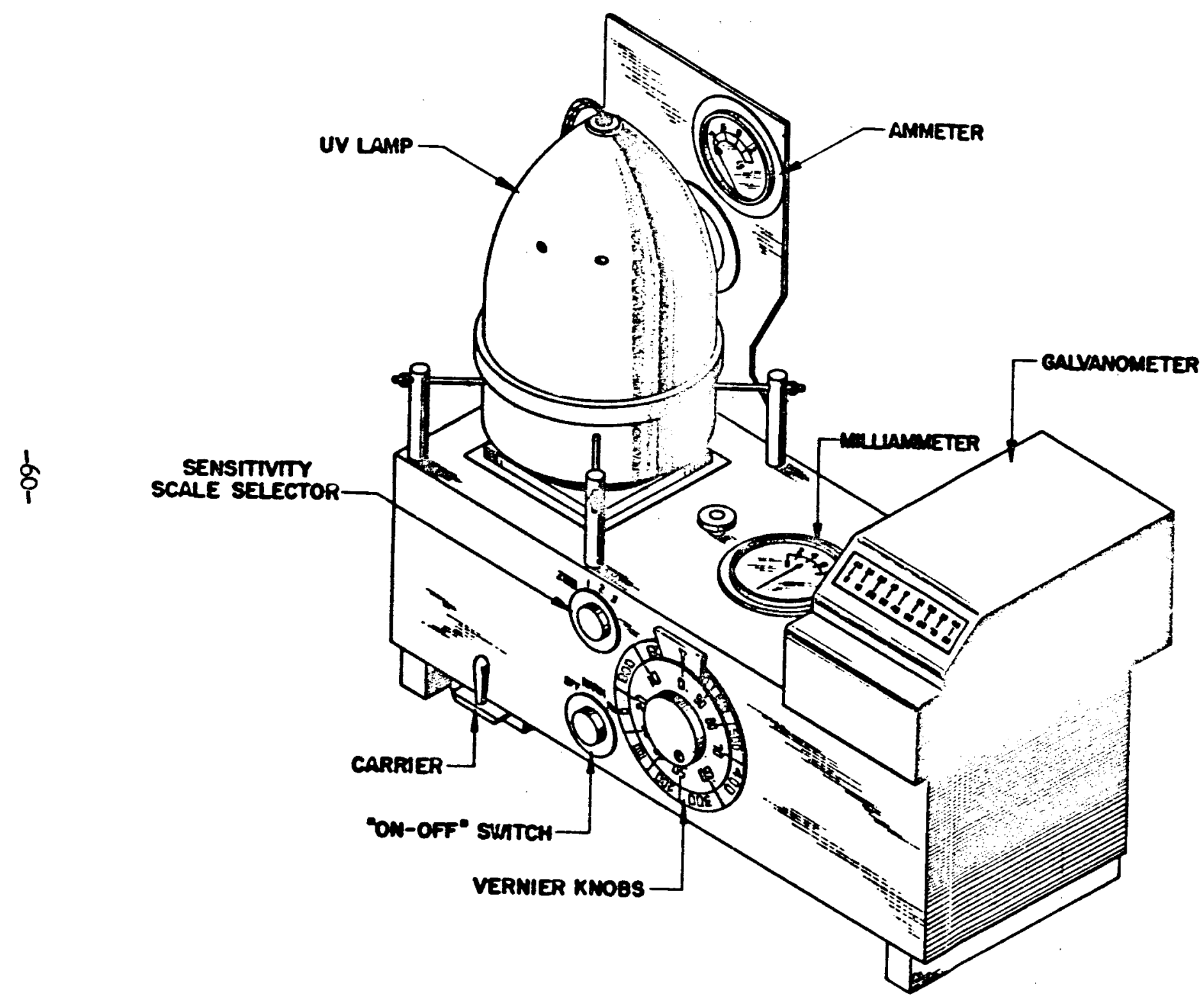

Fig. 1 - Extermal view of the Auoropholometer.

Illustration was copied from IA-1858 


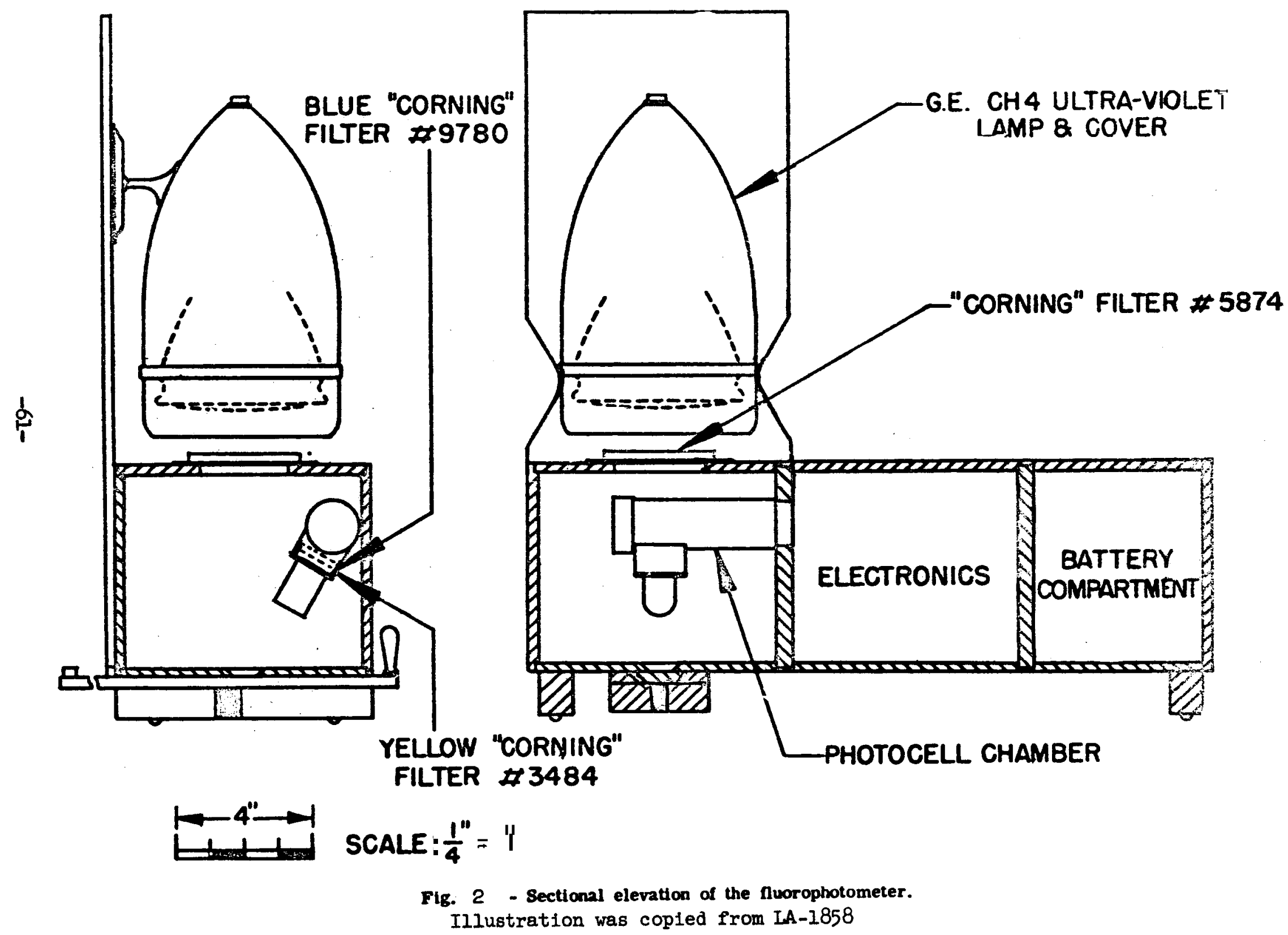




\section{$\operatorname{Method~} A^{(3)}$}

\section{$\underline{\text { Procedures }}$}

1. If urine samples are clear proceed with step 2 . Cloudy urine samples are treated with 1\% by volume conc. $\mathrm{HCl}$ and allowed to stand overnight. Those not clear are wet ashed with $\mathrm{BNO}_{3}$ and $\mathrm{H}_{2} \mathrm{O}_{2}(30 \%)$ and made up to original volume with distilled water.

2. Pipet three $0.1 \mathrm{ml}$ aliquots of the urine sample into the depressions of three platinum fluorimeter dishes.
3. Place the dishes on a transite board over a medium heat hot plate and evaporate to dryness.
An unclear sample may prevent the taking of a uniform sample.

Fluorimeter dishes are fabricated from 1" diam. x $0.015^{\prime \prime}$ thick platinum disks and are formed at the center with a circular depression $0.50^{\prime \prime}$ diam. x 0.150" deep.

Dishes are cleaned daily. the fused flux is removed by washing with hot water, the dishes are then placed in hot 1:1 ENO 3 for at least 15 minutes, washed with water and dried. The dishes are next fused with potassium bisulfate and this flux washed off with warm water. The dishes are stored in 1:1 $\mathrm{BNO}_{3}$ and are washed with distilled water and dried over a flame before being used.

Three dishes are selected at random and a blank determination run. If one or more show a high reading the entire batch is recleaned.

Care is taken to prevent spattering. 

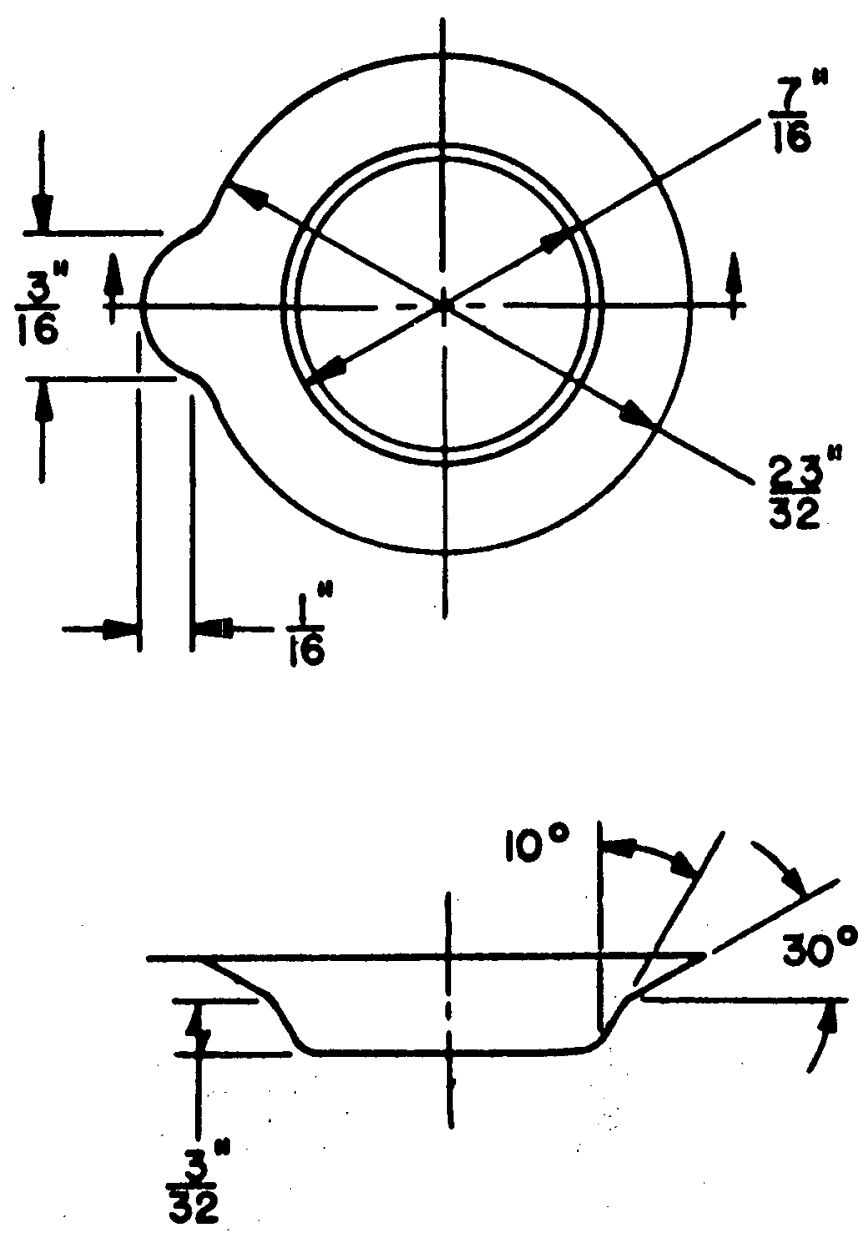

\section{MIL PLATINUM}

Fig. 3 - Platinum dishes.

Illustration was copied from LA-1858 
Procedure

4. Char the residue over a meker burner.

5. Cool and add $80 \pm 20$ mg. of sodium fluoride.

6. Fuse completely over the meker burner and cool.

7. Re-fuse and cool.

8. Prepare triplicate blanks according to steps 4 , 5 and 6.

9. Read the fluorescence of each sample and blanks.

\section{Procedure Notes}

The gas supply is regulated to a pressure of $45 \mathrm{~cm}$ of $\mathrm{Hg}$ using a booster pump and pressure regulator.

The dish is supported in a two-pronged fork made of $2 \mathrm{~mm}$ platinum rod mounted on a sTifolequipoed stand to facilitate positianing of the dist over the burner.

Sodium fluoride is added as a pellet from a dispenser made by cutting a $1 \mathrm{ml}$ hypodermic syringe to leave the full bore open. The plunger is raised to a pre-determined level and the syringe tamped in a small supply of sodium fluoride pre-tested for fluorimetric suitability.

The dish is cooled by holding the dish bottom against a clean metal surface.

The dishes are placed in a transite rack with holes bored to accomodate the dishes. Steps 5 and 6 should be carried out i n 25-30 seconds, daily.

Cne set of blanks is prepared

Repeated blanks on the same group of dishes with thorough cleaning in between, does not reduce the blank below a value corresponding to about $10^{-9}$ grams of uranium per dish. However, for a given batch of flux, this value is reproduced $t o \pm 3 \times 10^{-10}$ 
$\underline{\text { Procedure }}$

10. Determine the quantities of uranium in the samples from a calibration curve or factor obtained from prepared uranium standards.
Procedure Notes

grams. In a 11 analyses, triplicates are run and the median value used in calculations. (The medien sample reading is corrected by subtracting the medan blank reading.)

Standards are prepared daily and each time a fresh bottle of sodium fluoride is put into use. The standards are prepared by pipetting suitable portions of standard uranium solutions onto platinum dishes and treating as described for samples. Standard solutions are prepared from a stock solution $(500 \gamma-\mathrm{gamm} / \mathrm{ml})$ by dissolving $58.9 \mathrm{mg}$ of pure $\mathrm{U}_{3} \mathrm{O}_{8}$ in $2 \mathrm{ml}$ of conc. $\mathrm{HNO}_{3}$ and evaporating to dryness, next taken up with distilled water containing 10 drops of $\mathrm{HNO}_{3}$ and transferred to $100 \mathrm{ml}$ volumetric flask and diluted to volume.

For preparing the calibration curve, three standards are used in each instrument range.

It is important that the standard solutions made up from the stock solution be slightly acid to prevent hydrolysis and adsorption of uranium.

Method A is adapted primarily from those procedures utilized by the Analytical Branch, Health and Safety Division, New York Operations, U.S. A.E.C. (See reference 3.) 
$\underline{\text { Procedure }}$

1. Two clean dry platinum dishes for each sample are placed on lava trays. In addition four pair of blank dishes are set up daily. (Two peir of the blank dishes are used to obtain an unquenched blank reading, the other two pair to obtain, when spized, a reading vs millimicron uranium relationship (unquenched))

2. 0.1 ml of a working standard uranium solution is transferred into one of each pair of dishes.

3. A $0.02 \mathrm{ml}$ aliquot of each urine sample is pipetted first into an empty dish and then into the spiked dish.

4. Place each lava tray of dishes under an infra red lamp and char samples,
Procedure Notes

Platinum tipped forceps are used to handle clean dishes. A 11 equipment which comes into contact with the dishes is cleaned daily. Platinum dishes (see figure 3,) are cleaned by first removing the fused button by tapping gently or by heating in cone. $\mathrm{H}_{2} \mathrm{SO}_{4}$. The dishes are then boiled a few minutes in a mixture of $10 \%$ cone. Hydrofluoric Acid. $70 \%$ conc. BCl and $20 \%$ water, rinsed thoroughly in distilled water and dried, Clean dishes are stored under distilled water in a closed container.

The stock standard solution is prepared by dissolving $1.7700 \mathrm{~g}$ of $\mathrm{U}_{308}$ in $10 \mathrm{ml}$ of conc. ECI and then diluting to 1 liter with distilled $\mathrm{B}_{2} \mathrm{O}$ 。 A working standard uranium solution is prepared by pipetting a 1 m aliquot of the stsek solution into a liter flask, adding $65 \mathrm{ml}$ conc. $\mathrm{HNO}_{3}$ and diluting to volume with distilled $\mathrm{H}_{2} \mathrm{O}$. The solution is stored in a polyethylene bottle.

Each specimum is shaken vigorously immediately before the aliquot is taken to obtain uniform sampling. Care is taken to keep the pipette from touching the bottom of the spiked dish.

Heat is applied gently with the lamps 6 to 8 inches above the trays until the liquid is removed and the samples have started to char. The lamps are then lowered to $1 / 2^{\prime \prime}$ above 


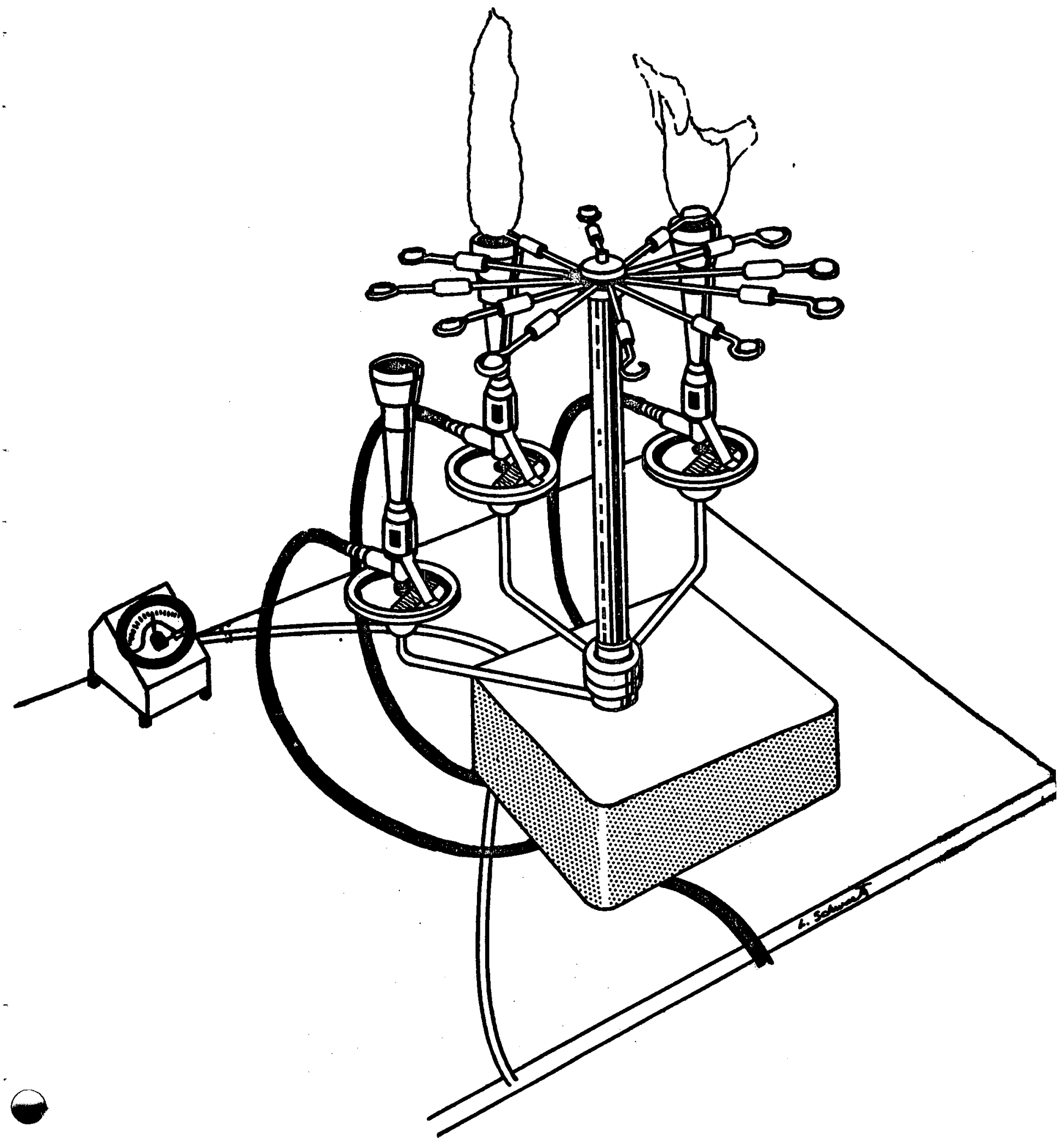

Fig. 4 - Three burner fusion device. Illustration redrawn from Ref. 2. $-67-$ 
$\underline{\text { Procedure }}$

5. Remove the trays from the lamps and add a pellet of sodium fluoride (about $0.3 \mathrm{~g}$ ) to each dish,

6. Place the dishes on the wheel of the three burner fusion device (see illustration) and allow to pass through the complete fusion cycle.

7. Transfer the dishes, in order, to the semple carrier of the fluorophotometer.

8. Measure and record the ruorescence of each dish.

9. Calculate the quantity of uranium/ aliquot from the fluorescence reading. $\underline{\text { Procedure }} \underline{\text { Notes }}$

the trays and the samples are charred completely. At least one half' hour is required for the final charring.

A pellet dispenser is readily made from an 8-a length of a $10 \mathrm{vI}$ graduated pipette and a $10.5 \mathrm{~m}$ length glass rod that slides easily but not loosely inside the tube.

The fusion device (see figure 4) is adjusted to advance 1/12 rev. every 90 seconds. The fusion cycle is: (1) fusion at dish temperature of $1000^{\circ} \mathrm{C}$, (2) air cooled, (3) re-fused at $1000^{\circ} \mathrm{C}$, (4) annealed at $800^{\prime} \mathrm{C}$.

To avoid confusion, one carrier on the wheel is left empty between unfused and finished dishes. Each finished dish is removed fromthe fusion device and returned to its original position on the lava tray. The full tray is allowed to cool $45 \pm 15$ minutes. Slight variations in fuorescence may be encountered if cooling time is not reasonably consistent.

The dark current of the fluorophotometer is balanced against a clean platinum dish and the sensitivity adjustsd to the proper level.

The uranium concentration in the sample aliquot, corrected for quenching effects in the sample, is calculated as follows:

millimicrograms U/aIlquot $=\frac{\text { AS }}{D-A}-\frac{B}{C}$ 
$\underline{\text { Procedure }}$

Procedure Notes

Where: sample.

$A=$ Gross reading of unspiked reading.

$\mathrm{B}=$ Average unquenched blank

$\mathrm{C}=$ The average reading for 1

millimicrogram of uranium (un-

quenched)。 sample.

$\mathrm{D}=$ Gross reading of spiked

$\mathbf{S}=$ Millimicrograms uranium spike. (This should be at least 10 times the sample concentration.)

Method B is based primarily on procedures used at the Union Carbide Nuclear Company, Y-12 Plant. (See reference 2.)

111. Enriched Uranium Urinalysis. Due to its higher specific activity, enriched uranium urinalysis is based upon a radioactive rather than a fluorophotometric determination. The procedure involves digesting the urine, removal of some interfering cations and the electroplating of the uranium onto nickel disks. The alpha activity on the disks is then measured on a proportional counter. 6 The sensitivity of the counting method depends on the counter background. Proportional counters ma be maintained in routine use with backgrounds from 10 to 15 counts per hour i.e., from 0.16 to 0.25 c.p.m. Blank disks are counted overnight. Experimental disks are counted for 20 minutes in each of two amplifiers. It is estimated by the reviewers that recovery from urine samples in the activity range of interest will be about $70 \%$ or better.

Procedure

1. Pour a $100 \mathrm{~m} \mathrm{I}$ aliquot of urine into a $400 \mathrm{ml}$ beaker and gad $50 \mathrm{ml}$ of concentrated $\mathrm{HNO}_{3}$.

2. Cover the beaker with a watch glass and evaporate to dryness on a hot plate. $\underline{\text { Procedure Notes }}$

The digestion process serves to remove organic materials which might complex with uranium and interfere with plating. 
Procedure

3. Add 5 - $10 \mathrm{ml}$ of concentrated $\mathrm{HNO}_{3}$ and evaporate to dryness again.

4. Ignite the residue cautiously over a blast burner until only a white salt remains.

5. Add $10 \mathrm{ml}$ of concentrated $\mathrm{BnO}_{3}$ and reflux the sample for 5 minutes.

6. Remove the cover glass and continue the evaporation to near dryness.

7. Add 5 to $10 \mathrm{~m} \mathrm{I}$ of distilled water and transfer to a $50 \mathrm{~m}$ I centrifuge tube.

8. Add $5 \mathrm{~m} \mathrm{I}$ of the $0.4 \mathrm{M}$ ammonium oxalate solution and 5 drops of Thymol Blue indicator to the tube.

9. Add Ammonium $\boldsymbol{H y}$ droxide dropwise with stirring to the tube until the indicator changes from pink to blue.

10. Add an additional $5 \mathrm{ml}$. of the $0.4 \mathrm{M}$ ammonium oxalate solution and centrifuge it for $2-3$ minutes.

11. Decant the supernate into an assembled cell stack.
Procedure Notes

Personal attention is needed at this point to avoid spattering.

Ammonium oxalate solution - $0.4 \mathrm{M}$ is prepared by dissolving 56.8 grams of ammonium oxalate in 1 liter of distilled water. Thymol Blue indicator solution is prepared by dissolving $0.1 \mathrm{~g}$. of the reagent in distilled water, adding $4.3 \mathrm{ml}$ of $1 / 20-\mathrm{N} \mathrm{NaOH}$ and adjusting to $100 \mathrm{ml}$ with distilled water.

In order to adjust pH to approximately 8 , to get quantitative precipitation of the heavy metals including calcium. Ammonium oxalate has been found to be a successful electrolyte for plating uranium.

The maximum speed of the clinical centrifuge is used.

The cell stack assembly is similar to the one used by Cohen and Hull 6, 7 and consists of cell, rubber gasket, base plate and rubber bands for holding the cell in position on the base plate. 
Procedure

12. Dissolve the residue with a few drops of $\mathrm{ENO}_{3}$, add 2 - $3 \mathrm{ml}$ of the ammonium hydroxide solution and adjust the p E as in step 9 .

13. Add an additional $2 \mathrm{ml}$ of the ammonium oxalate solution and centrifuge for 2 - 3 minutes,

14. Transfer the supernate to the cell stack and add $5 \mathrm{ml}$. of ferric sulfate solution to the combined supernates.

15. Place the cell stack in a water bath, which is maintained at $80^{\circ} \mathrm{C}$ and procede with the electroplating.

16. After 40 minutes of plating, add $10 \mathrm{~m} \mathrm{I}$ of the ammonium oxalate solution and continue the plating for an additional 20 minutes.

17. At the conclusion of the plating period remove the cell stack, decant the plating solution and disassemble the cell stack.

18. Wash the plated nickel disk with a damp piece of kleenex and dry with alcohol.
Procedure Notes

Any uranium occluded by the precipitate is recovered by procedures 12 and 13.
Ferric sulfate solution is prepared by dissolving 39.3 of of ferric sulfate in $100 \mathrm{~m} \mathrm{I}$ of distilled water. Iron is added as a co-plating metal. It apparently prevents redissolving of the plated uranium.

The multiple plating unit used is one described by McAuliffe 8 and used in conjunction with a current rectifier capable of producing 12 amperes at 30 volts。

The uranium is plated on nickel disss $2-3 / 8^{\prime \prime}$ in diameter and $0.025^{\prime \prime}$ thick.

To readjust current density to its former value. 
Procedure

19. Ignite the disk for 10 minutes at $800^{\circ} \mathrm{F}$.

20. The alpha activity of the plate is now counted electronically.

21. The net counting rate is determined by subtracting the blank disk counting rate from the experimental disk counting rate and applying a counting efficiency plus recovery factor to convert to disintegrations per minute.
Procedure Notes

The counting is carried out on a conventional proportional counter with backgrounds in the neighborhood of 12 counts per hour, using standard counting techniques and utilizing statistical methods to evaluate the counting results,

This method is based primarily on procedures used at the Union Carbide Nuclear Company, K-25 Plant. (6). 
IV. Bibliography.

1. Voegtlin, Carl and Hodge, H.C. Pharmacology and Toxicology of Uranium Compounds. N.N.E.S.VI, Vol. 1, Part I, MeGraw-Bil1 Book Company, New York 1953.

2. Union Carbide Nuclear Company. Y-12 Plant Laboratory Division Procedure Manual.

3. Alercio, John, Fot1, Stephen and Fast, Jo Fluorimetric Uranium Determination in Urine. Report No. 4, Analytical Branch, Health and Safety Division, New York Office, U.S. A。E。C.

4. Los Alamos Scientifie Laboratory. Analytical Procedures. LA-1858, August 1955.

5. Galvanek, Paul, Jr., Morrison, Thomas J., Jr. A New Fluorimeter for the Determination of Uranium. ACCO-47.

6. Union Carbide Nuclear Cotpany, K-25 Plant Laboratory Manual.

7. Cohen, B。 and Hull, D.E. The Counting Method of Isotopic Analysis of Uranium. Part 2, Report A-1235.

8. McAuliffe, C。 Quantitative Electroplating of Uranium for Isotopic Analysis Using Nickel and Monel as Base Metals. Report A-3626. 
Recommended Analytical Procedure for Radiostrontium

Reviewer -- John H. Harley

October 1958

(Editors Note: Dr. Harley has informed me that the World Health Organization at their conference, September, 1958, reviewed available strontium methods as well as other nuclides and recommended the preferred method reproduced below. It is a copy of the method given by Bryant et,al. (1957) in "Radiostrontium Fallout in Biological Materials in Britain" Atomic Energy Research Establishment, Harwell (England), AERE-HP/R 2056 (Amended).

I am further informed that in other deliberations of the above group the techniques reported Sr-90 in the HASI Manual of Standard Procedures USAEC Report $N Y O-4700$, were characterized as follows: "The method for the radiostrontium, determination in this manual is in every way the equivalent in sensitivity and precision of any other method; it gives detailed procedures for preliminary treatment (ashing, etc.) of a somewhat wider variety of matrices than is contained in Method Strontium - $1^{n}$.

Dr. Harley agrees with the general opinion on these methods and would not recommend any other procedures at this time,)

\section{Details of Sampling Procedure.}

\section{A. Soil and Vegetation}

Samples of herbage and soil will be taken in the first fortnight of July each year, beginning in 1956. Half acre sites will be used on the chosen sampling farms, the same half acre being used each year.

\section{$\underline{\text { Grass }}$}

On the half acre, 10 plots, as near to one square yard as possible will be selected. The grass from each of the 10 plots will be out with shears to about "lawn-mower" length,.i.e., short enough to get the vegetation that a sheep would graze but long enough to avoid contaminating the grass sample with soil. The grass from the 10 sites will be bulked. If the bulk sample falls appreciably below 5 lbs. in weight, more yard plots will be cut, the total number being recorded.

Mat

After the grass has been cut, a core of any grass mat there might be present will be taken from each 10 plots, and bulked. A 
sampling tool will be used giving a $4^{\prime \prime}$ diameter core.

$\underline{\text { Soil }}$

A $4^{\prime \prime}$ deep core of soil will be taken fromthe spot where the mat had been removed. In practice, a core of mat and soil ex-

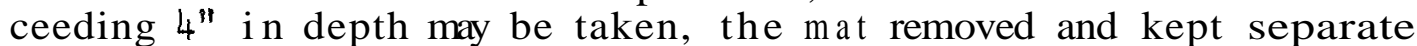
and the top $4^{\prime \prime}$ of the core retained as the soil sample. The sample from the 10 plots may be bulked. The exact surface area must be noted.

In each future year, new square yard plots as near as possible to the original plots, but not overlapping them, should be chosen.

\section{B. Sheep}

The sheep to be taken should be in the region of 15 months old. It will have to he accepted that some sheep would spend part of their lives on pastures possibly remote from the sampling site. It is important, however, that the sheep should have spent at least the last few months in grazing pastures on or near the sampling site. Long bones only will be required.

Bones should be cleared of surface meat but need not be otherwise treated.

C. Other Information

Samplers will be asked to provide:-

(a) Details of terrain, rainfall, etc.

(b) Details of sheep management (i e.. whether sheep had grazed in sampling pasture continuously, and breed).

(c) Photographs of the site, and a "close-up" of the herbage.

D. Other Matters

(a) Reasonably level plots should be chosen for herbage and s o il samples.

(b) The plots need not be fenced off in any way unless the yield of grass per square yard is likelyto be less than $1 / 2-1 b$. In any case, cages should not be put in position more than 3 weeks before the sampling.

(c) Sites should remain unploughed for at least 5 years. 
IIa. Determination of Radiostrontium in Soil by Hydrochloric Acid Extraction,

$\mathbf{t}$ of III

The soil is stirred, in the presence of strontium carrier, with two successive quantities of $M$ hydrochloric acid. The insolubie material is filtered off and calcium and strontium precipitated as oxalates at a controlled pir of 4 .

The solution will contain appreciable amounts of aluminium in the case of clay soils and by complexing the oxalate ion the aluminum will prevent the precipitation of calcium and strontium. With such soils the solution is first neutralized (before addition of the oxalic acid) with sodium hydroxide and excess sodium hydroxide added to make the solution IN in free alkali。 Sodium carbonate is added to precipitate the calcium and strontfum and the carbonates filtered off. The carbonates are dissolved in dilute acid, oxalic acid added and the pH adjusted to 4.0 when calcium and strontium are Precipitated.

The oxalates are ignited and the calcium and strontium dissolved in dilute acid. Any residual iron and aluminium are removed as hydroxides and the calcium and strontium precipitated as carbonate and weighed.

The strontium is separated from the calcium by successive 75 per cent nitric acid separations. Two barium chromate separations are made after additions of barium carrier and followed by an iron scavenge to remove radium and its daughters. Yttrium carrier is added, and after a period of time for the $Y 90$ to grow in, the yttrium is milked off and counted.

Special Reagents Required

(i) Fuming nitric acid, 95-96 per cent $\mathrm{w} / \mathrm{w}$

(ii) Nitric acid 3.5M; Add $126 \mathrm{ml}$. $16 \mathrm{M}$ nitric acid to $460 \mathrm{ml}$. distilled water.

(iii) Dilute acetic acid, 6M。

(iv) Ammonium acetate solution., 3M

(v) Sodium chromate solution $1.5 \mathrm{M}$

(vi) Oxalic acid solution, 8 per cent,

(vii) Strontium carrier solution, 40 mgr. Sr per $\mathrm{ml}$ standardized.

(vi1i) Yttrium earrfer solution, 10 mgm。Y per ml. standardized.

(ix) Barium carrfer solution, 10 mon. Ba per ml.

(x) Ferric iron carrier solution, $5 \mathrm{mgm}$. Fe per $\mathrm{ml}$. 
Procedure

1. Weigh $500 \mathrm{gm}$ dry soil into

1 liter beaker. Add $250 \mathrm{ml}$. distilled water and $10 \mathrm{ml}$. strontium carrier solution. Stir and add $250 \mathrm{ml}$. IIM hydrochloric acid (Note (a)). Allow to stand with occasional stirring for at least 8 hours. Transfer the contents of beaker to a large Buchner funnel provided with a Whatman No, 54 filter paper. Filter and wash the soil with about $500 \mathrm{ml}$. distilled water. Return the soil to the original beaker and treat with a further 250 $\mathrm{ml}$. water and $250 \mathrm{ml}$. hydrochloric acid. After the second period of extraction is completed, filter and wash as before. Reject the soil.

Combine the two filtrates in a 4 liter beaker.

2. Add $100 \mathrm{gm}$. oxalic acid and $25 \mathrm{ml}$. 50 per cent ammonium acetate solution. Warm to dissolve the oxalic acid and neutralize by the addition of amonium hydroxide until a $\mathrm{pH}$ value of 4.0 is obtained (Note (b)). Stand the solution in a warm place for at least 4 hours. Remove the supernate by suction and filtration. If the precipitate is discoloured due to iron, dissolve in 6-8 M nitric acid, dilute to about 1 liter, add $50 \mathrm{gm}$. oxalic acid and reprecipitate at $\mathrm{pH} 4.0$.

3. Transfer the oxalate precipitate to a silica dish, dry in an oven and ignite in a muffle furnace at $700-800^{\circ} \mathrm{C}$ for 30 minutes. Remove from furnace and allow to cool completely. Add 50-60 ml. water and dissolve the residue by addition of I6M nitric acid. Transfer the solution to a $400 \mathrm{ml}$. beaker and boil to remove carbon dioxide, Dilute to about $200 \mathrm{ml}$. Add ammonium hydroxide
Procedure Notes

(a) Caution should be used during the addition of hydrochloric acid for soils of high calcium content. (b) If a brown precipitate is obtained before $\mathrm{p} Z 4$ is reached, there is insufficient oxalate present to complex a 11 the iron. Add a further $50 \mathrm{gm}$. oxalic acid and again adjust the $\mathrm{pH}$. The $\mathrm{pH}$ is conveniently determined with $\mathrm{p}$ \& papers. 
$\underline{\text { Procedure Notes }}$

to the hot solution to precipitate any iron and aluminium. Filter through a $15 \mathrm{~cm}$ Whatman No. 41 filter paper and wash the precipitate with hot water.

4. Add solid ammonium carbonate to the filtrate until precipitation of calcium and strontium is complete, Filter the carbonates on a suitable size filter paper, dry and weigh (Note (c)). This weight gives the calcium carbonate content of the soil plus the weight of strontium carbonate carrier recovered.

5. Dissolve the mixed carbonates in the minimum of $3.5 \mathrm{M}$ nitric acid. Measure $58 \mathrm{ml}$. portions of this solution into $200 \mathrm{ml}$. centrifuge bottles. To each bottle add $120 \mathrm{ml}$. fuming nitric acid with stirring. The residual volume of solution is treated with a proportionate amount of fuming nitric acid (Note (d)). Cool in running ,water for 30 minutes stirring occasionally. Centrifuge and remove supernatant acid (Note (e))。

6. To each centrifuge bottle add $40 \mathrm{ml}$. water, dissolve the residue and then add $90 \mathrm{ml}$. fuming nitric acid. Cool in water for 30 minutes, centrifuge and remove the supernatant acid.

7. Repeat the procedure in para. 6. Transfer the residues to a $40 \mathrm{ml}$. centrifuge tube with 10-20 ml. water. Add $1 \mathrm{ml}$. barium carrier solution and 1 drop methyl red indicator. Neutralize excess acid with 6M ammonium hydroxide and add $1 \mathrm{ml}$. $6 \mathrm{M}$ acetic acid and $2 \mathrm{ml}$. 3M ammonium acetate. Dilute the solution to $30 \mathrm{ml}$. and heat in (c) If the calcium content of the soil is low and the precipitate is not much greater than that expected from the strontium carrier alone, the drying and weighing may be omitted and the calcium determined later (Note (e)).

(d) $58 \mathrm{ml}$. of $3.5 \mathrm{M} \mathrm{nitric}$ acid dissolves approximately 10 gm. of calcium carbonate.

(e) If the weighing in para. 4 has been omitted, this supernate and subsequent one must be retained for calcium determination. See Addendum 2. 
boiling water bath. Add $2 \mathrm{ml}$. $1.5 \mathrm{M}$ sodium chromate solution and continue heating for 5 minutes. Centrifuge and filter through $7 \mathrm{~cm}$. Whatman No. $41 \mathrm{filte} r$ paper into a second Centrifuge tube.

8. Heat the second tube in the boiling water bath, add $1 \mathrm{ml}$. barium carrier solution, stir immediately, and heat for 5 minutes. Centrifuge and filter as before into another tube. Reject the two residueso Make the solution alkaline with 17M ammonium hydroxide, add solid amonium carbonate and heat to coagulate the carbonate precipitate. Centrifuge and reject the supernate.

9. Dissolve the residue in dilute nitric acid, add 1 drop 100 vol. hydrogen peroxide and $1 \mathrm{ml}$. iron carrier solution. Heat and stir to remove carbon dioxide. Dilute to 15-20 ml。and make alkaline with carbonate free ammonium hydroxide, heat and stir to complete precipitation. Centrifuge and transfer supernate to another $40 \mathrm{ml}$. centrifuge tube, Reject the precipitate.

10. A cidify the solution with QM nitric acid and add $1.00 \mathrm{ml}$. yttrium carrier solution. Cover the tube and store for at least 14 days.

11. Make the solution alkaline with carbonate-free ammonium hydroxide and heat in boiling water bath to coagulate precipitate, Centrifuge and transfer supernate to a second tube. Redissolve precipitate in $6 \mathrm{M}$ nitric acid, dilute to $10.15 \mathrm{ml}$. and reprecipitate with ammonium hydroxide. Centrifuge and add supernate to that from the previous precipitation. Mote time of first preeipitatfon. 
$\underline{\text { Procedure }}$

12. Redissolve precipitate in the minimum of $6 \mathrm{M}$ nitric acid and add $20 \mathrm{ml}$. 8 per cent oxalic acid solution. Heat in water bath for 10-15 minutes to produce a granular precipitate. Cool and filter through a Whatman No. 42 filter paper in a perspex filter stick, wash three times with methanol and mount on counting tray with "Gelva". Commence counting immediately.

13. Precipitate the strontium as carbonate from the combined supernates from para. $\mathbf{1 1}$ by adding ammonium carbonate and heating in a water bath. Cool and filter solution in a tared sintered glass crucible, porosity 4. Wash with water and methanol, dry in an oven at $110^{\circ} \mathrm{C}$. Weigh and calculate strontium yield.

14. When counting of yttrium source is completed remove paper with source from tray (Note (f)). Transfer to a tared crucible, burn off paper, ignite at $800-900^{\circ} \mathrm{C}$ and weigh as $\mathrm{Y}_{2} \mathrm{O}_{3}$.

15. Calculate yttrium recovery. Correct the yttrium count at zero time for strontium and yttrium yields. Convert to disintegration rate using counter efficiency obtained in Addendum 3. $\underline{\text { Procedure Notes }}$ (f) Application of gentle heat from a hot plate to the tray will soften the Gelva sufficiently to enable the paper complete with source to be removed.

\section{Addenda}

1. Modification for soils of high aluminium content.

Extract the soil as in para. 1 of procedure. Combine the filtrates and neutralize with IOM sodium hydroxide solution. Dissolve $50 \mathrm{gm}$ sodium hydroxide and $50 \mathrm{gm}$ sodium carbonate in water and add to the solution, stand with occasional stirring for an hour and remove supernate by suction and by filtration on a bucher funnel through a Whatman 
No. 54 filter paper. Dissolve the precipitate in dilute hydrochloric acid and continue from para. 2 of the Procedure.

2, Determination of calcium content of soils.

For soils of high calcium content the weight of the mixed carbonates obtained in para. 4 is corrected for the weight of strontium carbonate obtained in para. 13 and the calcium content calculated.

To determine the calcium content of soils low in calcium evaporate the nitric acid supernates from para, 5 and 6 to low bulk and dilute with water to $40-50 \mathrm{ml}$. Add 8 per cent oxalic acid solution and adjust the p $\mathrm{p}$ to 4.0. Stand the solution 3-4 hours. Filter in a tared, sintered-glass crucible (porosity 4), wash with water and methanol, and dry in an oven at $110-115^{\circ} \mathrm{C}$ for 30 minutes. Weigh as calcium oxalate monohydrate - factor 0,2743 .

\section{Calibration of Counter for Y90.}

To tubes containing $10 \mathrm{mgm}$. each of strontium and yttrium carriers, add known aliquots of standardized $5 r 90$ solution, Store for a minimum of 18 days and then continue as in para. 11, 12 and 14 of ProcedureCorrect the yttrium source count rate at zero time for yttrium recovery and calculate counter efficiency from known disintegration rate of aliquot 。

II.b. Determination of Radiostrontium in Soil by Fusion with Sodium Hydroxide and Sodium Carbonate.

Outline of Method

The soil, in the presence of strontium carrier, is fused with sodium hydroxide and sodium carbonate. The insoliuble matter remaining after leaching with water is dissolved in perchloric acid and evaporated to dehydrate the silica, The silica is filtered off and the strontium and calcium precipitated from the filtrate as oxalates at a controlled pH of 4.

The solution will contain appreciable amounts of aluminium in the case of clay soils and by complexfng the oxalate ion the aluminium will prevent the precipitation of calcium and strontium. With such soils the solution is first neutralized (before addition of the oxalic acid) with sodium hydroxide and excess sodium hydroxide added to make the solution IN in free alkali. Sodium carbonate is added to Precipitate the calcium and strontium and the carbonates filtered off. The carbon-

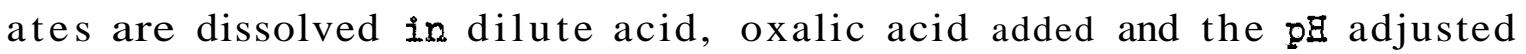
to 4.0 when calcium and strontium are precipitated. 
The oxalates are ignited and the calcium and strontium dissolved in dilute acid. Any residual iron and aluminium is removed as hydroxide and the calcium and strontium precipitated as carbonate and weighed.

The strontium is separated from the calcium by successive 75 per cent nitric acid separations, Two barium chromate separations are made after additions of barofum carrier and followed by an iron scavenge to remove radium and its daughters. Yttrium carrier is added and after time for the $\mathrm{Y}^{90}$ to grow in the yttrium is milked off and counted.

\section{Special Reagents Required}

(i) Fuming nitric acid, 95-96 per cent $\mathrm{w} / \mathrm{w}$.

(ii) Nitric acid 3.5M; Add $126 \mathrm{ml}$. $16 \mathrm{M}$ nitric acid to $460 \mathrm{ml}$. distilled water.

(iii) Dilute acetic acid 6M。

(iv) Ammonium acetate solution, 3M。

(v) Sodium chromate solution $1.5 \mathrm{M}$.

(vi) Oxalic acid solution, 8 per cent.

(vii) Strontium carrier solution, 40 mom。 $\mathrm{Sr}$ per ml. standardized.

(viii) Yttrium carrier solution, 10 mom. Y per ml. standardized.

(ix) Barium carrier solution, 10 mgm。B per ml.

(x) Ferric iron carrier solution, 5 mgm。Fe per ml.

\section{EXPERIMENTAL}

\section{Procedure}

Procedure Notes

1. Weigh $50 \mathrm{gm}$. portions of soil into each of two silica basins, Ignite in muffle furnace at $800-900^{\circ} \mathrm{C}$ until organic matter has been burnt off. Cool and add $5 \mathrm{ml}$. of strontium carrier solution to each dish. Dry in oven.

2. Weigh $150 \mathrm{gm}$. sodium hydroxide into $250 \mathrm{ml}$. nickel crucible and heat in a gas muffle furnace until molten. Add small portions of the soil from one of the silica basins to the molten sodium hydroxide controlling the heating and rate of addition of the soil to prevent frothing over.

When all the soil has been transferred to the crucible add $10 \mathrm{gm}$. sodium carbonate, Raise the temperature and stir with an iron or copper wire until a homogeneous melt is obtainedo 
$\underline{\text { Procedure }}$

Allow the crucible to cool

with the stirrer imhedded in the melt.

3. Treat the second portion of soil similarly as described in para. 2. Extract the two melts in 2 liter beakers using about 1 liter of water (Note (a)). When the dissolution of the fused mass is complete, allow the insoluble matter to settle and remove the supernatant liquid by suction and filtration. Transfer the insoluble matter to two shallow beakers using about $100 \mathrm{ml}$. of water in each., Stir the contents until a fine slurry is obtained free from large lumps and add $200 \mathrm{ml}$. 60 per cent perchloric acid to each beaker.

4. Evaporate the solutions under infra red lamps, stirring occasionally to break up the gelatinous masses of silica. Continua the heating until a powder is obtained. Extract the residues with about $200 \mathrm{ml}$. $2 \mathrm{M}$ hydrochloric acid. Filter the solutions through the Buchner funnel fitted with a Whatman No. 54 filter paper. Wash the filter with distilled water and combine the filtrate in a 2 liter beaker.

(Note (b)).

5. Continue as in para. 2 of Procedure for the hydrochloric acfd extraction method for soil.

II.c. Determination of Radiostrontium in Soil by Ammonium Acetate Extraction.

Outline of Method

The soil is stirred with neutral amonium acetate solution. The soil is filtered off, strontium carrier adied to the filtrate and the calcium and strontium precipitated by the addition of sodium carbonate. The mixed carbonates are ignited, the calclum and strontium dissolved in dilute acid. Any residuel iron is precipitated as hydroxide and filtered off together with any silica. The calcium and strontium are (a) The cold crucible is heated rapidly and the still solid melt removed from the crucible by pulling, on the stirrer. (b) For soils of high aluminium content treat as in Addendum 1 of the hydrochloric acid method before proceeding. 
reprecipitated as carbonate and weighed.

The strontium is separated fromthe calcium by successive 75 per cent nitric acid separations. Two barium chromate separations are made after additions of barium carrier and followed by an iron scavenge to remove radium and its daughters. Yttrium carrier is added and after a period of time for the $Y 90$ to grow in the yttrium is milked off and counted.

$\underline{\text { Special Reagents Required }}$

(1) Ammonium acetate solution, $I M$, adjusted to $p \# 7.0$

(ii) Fuming nitric acid, $95-96$ per cent w/w.

(iii) Dilute acetic acid $\mathrm{M}$

(iv) Ammonium acetate solution, 3M.

(v) Sodium chromate solution, $1.5 \mathrm{M}$.

(vi) Oxalic acid solution, 8 per cent.

(vii) Strontium carrier solution, 40 mgm. Sr per ml. standardized.

(viii) Yttrium sarrier solution, $10 \mathrm{mgm}$. Y per ml. standardized.

(ix) Barium carrier solution, $10 \mathrm{mgm}$. Ba per $\mathrm{ml}$.

(x) Ferric iron carrier solution, $5 \mathrm{mgm}$. Fe per $\mathrm{ml}$.

\section{EXPERIMENTAL}

Procedure

1. Weigh $250 \mathrm{gm}$. portions of soil into each of two 2.5 liter bottles. To each bottle add 2 liters IM ammonium acetate solution and allow to stand with periodic agitation for 5-7 days. (Note (a)).

2. Filter the solution on a Buchner funnel fitted with a Whatman No. 54 filter paper and transfer the combined filtrates to a 5 liter beaker. Add $10 \mathrm{ml}$. strontium carrier sclution, warm and then add $100 \mathrm{gm}$. sodium carbonate whilst stirring. Allow to stand 8-16 hours.

3. Remove the supernatant solution by suction and filtration through a $15 \mathrm{~cm}$. Whatman No. 40 filter paper. Reject the filtrate, Transfer the filter paper to a platinum dish, dry in an oven and ignite at $800-900^{\circ} \mathrm{C}$ in a muffle $\underline{\text { Procedure Notes }}$

(a) The bottles may be conveniently agitated during the working day and allowed to stand overnight. 
$\underline{\text { Procedure }}$

furnace for 30 minutes. Allow to cool. Add 50-60 ml. water and dissolve the residue by addition of 16M nitric acid. Transfer to a 400 $\mathrm{ml}$. beaker and boil to remove carbon dioxide. Dilute to about $200 \mathrm{ml}$. and add ammonium hydroxide to the hot solution to precipitate any iron and aluminium. Filter through a Whatman No. 41 filter paper and wash the precipitate with hot water.

4. Add solid amonium earbbnate to the filtrate until precipitation of calcium and strontium is complete. Filter the carbonates on a suitable size filter paper, dry, and weigh. (Note (b)).

5. Transfer the carbonate precipitate to a $200 \mathrm{ml}$. centrifuge bottle together with $40 \mathrm{ml}$. distilled water. Add $90 \mathrm{ml}$. fuming nitric acid, a little cautiously at first to dissolve the carbonates and then the remainder to precipitate the strontium. Cool in running water for 30 minutes, stirring occasionally.

Centrifuge and remove the supernatant acid (Note (e)). (b) If the calcium extracted is small and the precipitate is not much greater than that expected from the strontium carrier alone, the drying and weighing may be omitted and the calcium determined at the nitric and acid separation stage. (c) If the weighing in para. 4 has been omitted this supernate and subsequent one must be retained for calcium determination. See Addendum 2 of Section II. $\varepsilon$.

6. continue as in para. 6 of Procedure for the hydrochloric acid extraction method for soil. 
II. a. Determination of Radiostrontium in Animal Bone Ash.

Outline of Method

The bone ash is dissolved in nitric acid in the presence of strontium carrier. The nitric acid concentration is then increased to precipitate all the strontium. After further nitric acid separations, barium carrier is added and a barium chromate separation made. The separatea strontium is stored for at least 14 days in the presence of yttrium carrier; the yttrium is then milked and counted. The strontium is precipitated as carbonate and mounted for counting when further yttrium 90 has grown in.

$\underline{\text { Special Reagents Required }}$

(i) Fuming nitric acid, 95-96 per cent $\mathrm{w} / \mathrm{w}$.

(ii) Dilute acetic acid $\delta M$.

(iii) Ammonium acetate solution, 3M.

(iv) Sodium chromate solution, 1.5M.

(v) Oxalic acid, 8 per cent.

(vi) Strontium carrier solution, 5 st, Sr per ml. standardized.

(vii) Yttrium carrier solution, 10 . Y per $\mathrm{ml}$. standardized.

(viii) Barium carrier solution, 10 ast. Ba per ml.

(ix) Ferric iron carrier solution, 5 mow. Fe per $\mathbf{m l}$.

\section{EXPERIMENTAL}

\section{Procedure}

1. Weigh 5 bone ash into each of two $200 \mathrm{ml}$. centrifuge bottles. To each bottle add $5 \mathrm{ml}$. strontium carrier solution and $\mathbf{3 5 . 0}$

ml. water. Add 50.0 mi. fuming nitric acid and stir until all the sample has dissolved. Add a further $50.0 \mathrm{ml}$. acid gradually with stirring and cool in water for $\mathbf{3 0}$ minutes, stirring occasionally。

2. Centrifuge the two solutions and reject the supernates. Transfer the contents of one bottle to the other by means of $25.0 \mathrm{ml}$. water added from a pipette. To the combined residues add 57.0 ml. fuming nitric acid, and cool with stirring, for $\mathbf{3 0}$ minutes. Centrifuge and reject the supernate. Transfer the residue to a $40 \mathrm{ml}$. centrifuge tube with 20-30 ml, water.

\section{Procedure Notes}




\section{Pro edure}

3. Mese the solution in the centrifuge tube alkeline with ammonium hydroxide, add solid ammonium carbonate and heat in a boiling water bath to coagulate the carbonate precipitate.

Centrifuge and reject the supernate (Note (a)).

4. Add $10.0 \mathrm{ml}$. water to the residue in the centrifuge tube and then $22.5 \mathrm{ml}$. fuming nitric acid cautiously, Cool with stirring for 30 minutes, centrifuge and reject supernate.

5. Repeat paragraph 4. Dissolve the residue in 10-15 $\mathrm{ml}$. water, add $1 \mathrm{ml}$. barium carrier and 1 drop of methyl red indicator. Neutralize excess acid with $6 \mathrm{M}$ ammonium hydroxide and add $1 \mathrm{ml}$. M acetic acid and 2 ml. 3M ammonium acetate. Dilute the solution to $30 \mathrm{ml}$. and heat in boiling water bath (Note (b)). Add 1 ml. 1.5M sodium chromate and continue heating for 5 minutes. Centrifuge and transfer supernate to second centrifuge tube. Reject residue.

6. Make the solution alkaline with $17 M$ ammonium hydroxide, add solid ammonium carbonate and heat in boiling water bath to congulate the carbonate precipitate. Centrifuge and reject the supernate,

7. Dissolve the residue in dilutenitric acid, add $1 \mathrm{~d}$ rop 100 vol. hydrogen peroxide (Note $(\mathrm{c}))$ ). and add $1 \mathrm{ml}$. iron carrier. Beat and stir to remove carbon dioxide. Dilute to 15-20 ml. and make alkaline with carbonate-free ammonium hydroxide, heating for $2-5$ minutes to complete precipitation. Centrifuge and transfer supernate to another $40 \mathrm{ml}$. centrifuge tube. Rejeet precipitate. $\underline{\text { Procedure Notes }}$

(a) The carbonate precipitation serves to concentrate the strontium and calcium since more water is used in transferring than is required in the next segaration.

(b) The solution is diluted to reduce the loss of strontium which occurs in a more concentrated solution. 


\section{Procedure}

8. Acidify the solution with 6M nitric acid and add $1 \mathrm{ml}$.yttrium carrier solution. Cover the tube and store for at lesst 14 days.

9. Make the solution alkaline with carbonate free ammonium hydroxide and heat in boling weter bath to coagulate precipitate.

Centrifuge and transfer supernate to a second tube. Redissolve precipitate in $6 \mathrm{M}$ nitric acid, dilute to 10-15 mi. and reprecipitate with ammonium hydroxide. Centrifuge and add supernate to that from the previous precipitation. Note time of first precipitation.

10. Redissolve precipitate in the minimum of $6 \mathrm{M}$ nitric acid and add 20 ml. 8 per cent oxalic acid solution. Heat in water bath for 10-15 minutes to produce a granular precipitate. Cool and filter through a Whatmen No。 42 filter paper in a special Perspex filter stick, wash three times with methanol and mount on counting tray with "Gelva". Comenee counting immediately.

11. Precipitate strontium as carbonate fromthe combined supernates from paragraph 9 by adding anmonfum carborate and heating in a water bath, Cool and filter solution on a tared Whatman 42 filter paper in a filter stick (Note (d)). Wash with water and methanol suceessively, taking care to transfer the precipitate quatitatively to the paper. Separate the paper and its counterpoise, allow to come to equilibrium with the atmosphere for 2 hours and weigh the strontium carbonate. Calculate strontium yield. Court strontium source after
Procedure es 
Procedure

storing for a least 14 days. Correct the count by meas of the strontium recovery factor and colculate dis. integration rate of sample using counter efficiency obtained fa para. (a) of Addendum 1 .

12. When counting of yttrium source is completed remove paper with source from tray (Mote (e)). Transfer to a tared crucible, burn off' paper, ignite at $800-900^{\circ} \mathrm{C}$ and welgh as $\mathrm{Y}_{2} \mathrm{O}_{3}$ 。

13. Calculate yttrium recovery, Correct the ytitrium source count at zero time for strontium and yttrium yields. Convert the disintegration rate using counter fficiency obtained i n para. (b) of Addendum $I$.

$\underline{\text { Procedure Notes }}$

\section{Addenda}

1. Calibration of Couster for $Y 90$ and Sr90.
(a) Strostium carborate sources $(\mathrm{Sr} 90+\mathrm{Y} 90)$

To tubes conativing 25,40 and 60 mgroportions of strontium carrier, add known aliquots of standardized Sr 90 solution. Precipitate as carbonate, mount and weigh on tared Whatman 42 filter papers as in para. 11 of Erocedure, correcting recoveries for any strontium carrier in the standard solution. Allow sources to grow for about 18 days before countirg. Correct the count rates for recovery, and calculate counter efficlency from known disintegration rate of aliquct. Plot on log linesr paper graph of counter efficiency on log scale and source weight on linear scale.

\section{(b) Yttrium oxalate sources (Y90)}

To tubes contaluing 10 orm. each of strostiw and yttrium carriers, add knows aliquots of standardized Sr90 solution. Store for a minimum of 18 days and then continue as in para. 9, 10 and 12 of Procedure. Correct the yttrium source count rate at zero time (see para. 9) for yttrium recovery and calculate counter efficiency from known disintegration rate of aliquot.

\section{Determination of caleium content.}

Weigh accurately E gm. of ash into a $250 \mathrm{ml}$. beaker. Dissolve in approximately $40 \mathrm{ml}$. water and $5 \mathrm{ml}$. IIM hydrochloric acid. Heat 
to about $80^{\circ} \mathrm{C}$ and add $40 \mathrm{ml} .8 \mathrm{per}$ cent oxalic acid solution. Neutralize by the dropwise addition of $4 \mathrm{M}$ ammonium hydroxide to $\mathrm{pH} 4$. The $\mathrm{p} \mathbb{Z}$ value can be conveniently measured using bromocresol green indicator (green-blue colour), Stand the solution 3-4 hours and filter on a tared sintered glass crucible (porosity 4 ). Wash the precipitate with water and methanol and dry in an oven at $110-115^{\circ} \mathrm{C}$ for 30 minutes. The calcium is weighed as calcium oxalate monohydrate - factor 0.2743 . Calculate the calcium content of the bone ash.

\section{II.e. Determination of Radiostrontium in Human Bone Ash}

Outline of Method

The bone ash is dissolved in nitric acid in the presence of strontium carrier, The nitric acid concentration is then increased to precipitate all the strontium. After further nitric acid separations, barium carrier is added and a barium chromate separation made followed by a ferric hydroxide scavenge to remove any radium and its daughters. The strontium is precipitated as carbonate and mounted for counting after allowing time for $Y 90$ to grow in.

Special Reagents

(i) Fuming nitric acid, 95-96 per cent $\mathrm{w} / \mathrm{w}$.

(ii) Dilute acetic acid, 6M.

(iii) Ammonium acetate solution, 3M.

(iv) Sodium chromate solution, $1.5 \mathrm{M}$.

(v) Oxalic acid solution, 8-per cent.

(vi) Strontium carrier solution, $5 \mathrm{mgm}$. Sr per $\mathbf{l}$. standardized.

(vii) Yttrium carrier solution, 10 . Y per ml. standardized.

(vi1i) Barium carrier solution, 10 mst.Ba per $m$.

(ix) Ferric iron carrier solution, 5 . Fe per $\mathrm{ml}$.

\section{EXPERIMENPAL}

\section{Procedure}

$\underline{\text { Procedure Notes }}$

1. Weigh as much of the sample as is available, up to a maximum of $40 \mathrm{gm} .$, into a $200 \mathrm{ml}$. centrifuge bottle and add $5 \mathrm{ml}$. strontium carrier solution.

\section{2. (a) Sample weights less than}

Add $35.0 \mathrm{ml}$. distilled water and $50.0 \mathrm{ml}$. fuming nitric acid.

Stir until all the sample has dissolved. 
$\underline{\text { Procedure }}$

Add a further $50.0 \mathrm{ml}$ acid with stirring and cool in running water for 30 minutes, stirring occasionally. Centrifuge and reject the supernate.

Dissolve the residue in $40.0 \mathrm{ml}$. distilled water and add $90.0 \mathrm{ml}$. fuming nitric acid, Cool with stirring for 30 minutes as before, Centrifuge and reject supernate.

(b) Sample weights greater than $5 \mathrm{gm}$.

Add $45.0 \mathrm{ml}$. distilled water and $60.0 \mathrm{ml}$. fuming nitric acid. Stir until all the sample has dissolved, Add a further $60.0 \mathrm{ml}$. acid with stirring and cool in running water for 30 minutes, stirring occasionally. Centrifuge and reject the supernate.

Dissolve the residue in $50.0 \mathrm{ml}$. distilled water and add $113 \mathrm{ml}$. fuming nitric acid. Cool with stirring for 30 minutes as before. Centrifuge and reject supernate, Repeat the separation with these quantities $(50 \mathrm{ml}$. water, $113 \mathrm{ml}$. acid) until the residue is reduced to the amount expected from the strontium carrier along (Note (a)).

3. Transfer the residue to a $40 \mathrm{ml}$. centrifuge tube with 20-30 $\mathrm{ml}$. water. Continue as from para. 3 t 0 the end of para. 11 of Procedure for the determination of radiostrontium in animal bone ash, omitting para, 8-10.

4. Should the count rate be sufficiently high to enable the $Y^{90}$ to be determined proceed as follows:

Add $1 \mathrm{ml}$. yttrium carrier to a $40 \mathrm{ml}$. centrifuge tube. Detach the paper with source from the counting tray (Note (b)), and hold with forceps over the mouth of centrifuge

\section{Procedure Notes}


Procedure

tube. Detach the strontium source from the paper by dropwise addition of acetone, the volume of acetone added should not exceed $10 \mathrm{ml}$. Spot the filter paper with $\mathbb{M}$ hydrochloric acid, and wash with water into the centrifuge tube. Add sufficient acid to dissolve the carbonate precipitate and dilute with water to 25-30 ml.

5. Warm carefully and make the solution alkaline with carbonate-free ammonium hydroxide. Centrifuge and transfer supernate to a second tube. Redissolve precipitate in $\mathbf{M}$ nitric acid, dilute to 10-15 $\mathrm{ml}$. and reprecipitate with ammonium hydroxide, Centrifuge and add supernate to that from previous precipitation. Note time of first precipitation. (Note (c)).

6, Redissolve precipitate in minimum of $M$ nitric-acid-and add 20 ml. 8 per cent oxalic acid solution. Heat in water bath for 10-15 minutes to produce a granular precipitate. Cool and filter through a Whatman No, 42 filter paper in a special Perspex filter stick, Wash three times with methanol and mount on counting tray with Gelva. Commence counting immediately.,

7. When counting of yttrium source is completed remove paper with source from tray. Transfer to a tared crucible, burn off paper, ignite at $800-900^{\circ} \mathrm{C}$ and weigh as $\mathrm{Y}_{2} \mathrm{O}_{3}$.

8. Calculate yttrium recovery, Correct the yttrium count at zero time for strontium and yttrium yields. Convert to disintegration rate using counter efficiency obtained in para. (b) of Addendum 1. $\underline{\text { Procedure Notes }}$

(c) The supernates should be retained for further $Y$ milking if necessary. 


\section{$\underline{\text { Addenda }}$}

\section{Calibration of Counter for $\mathrm{Y}^{90}$ and $\mathrm{Sr}^{90}$.}

\section{(a) Strontium carbonate sources $(\mathrm{Sr} 90+\mathrm{Y} 90)$}

To tubes containing 25, 40 and $60 \mathrm{mgm}$. portions of strontium carrier, add known aliquots of standardized $5 r 90$ solution. Precipitate as carbonate, mount and weigh on tared Whatman 42 filter papers as in paragraph 11 of Procedure II.d., correcting recoveries for any strontium carrier in the standard solution, Allow sources to grow for about 18 days before counting. Correct the count rates for recovery and calculate counter efficiency from known disintegration rate of aliquot. Plot on log-linear paper a graph of counter efficiency or $\log$ scale and source weight on linear scale.

\section{(b) Yttrium oxalate sources $\left(\mathrm{Y}^{90}\right)$}

To tubes containing 10 mgm。 each of strontium and yttrium carriers, add known aliquots of standardized sr90 solution. Store for a minimum of 18 days and then continue as in paragraphs 9, 10 and 12 of Procedure II.d. Correct the yttrium source count rate at zero time (see paragraph 9) for yttrium recovery and calculate counter efficiency from known disintegration rate of aliquot.

\section{Determination of calcium content,}

Weigh accurately $1 \mathrm{gm}$. of ash into a $250 \mathrm{ml}$. beaker. Dissolve in approximately $40 \mathrm{ml}$. water and $5 \mathrm{ml}$. IIM hydrochloric acid. Heat to about $80^{\circ} \mathrm{C}$ and add $40 \mathrm{ml}$. 8 per cent oxalic acid solution. Neutralize by the dropwise addition of $4 \mathrm{M}$ ammonium hydroxide to $\mathrm{pH} 4$. The $\mathrm{pH}$ value can be conveniently measured using bromocresol green indicator (green-blue colour). Stand the solution 3-4 hours and filter on a tared sintered glass crucible (porosity 4)。Wash the Precipitate with water and methanol and dry in an oven at $110-115^{\circ} \mathrm{C}$ for 30 minutes, The calcium is weighed as calcium oxalate monohydrate - factor 0.2743 . Calculate the calcium content of the bone ash.

\section{II.f. Determination of Radiostrontium in Milk (Dried)}

Outline of Method

The milk is ashed to remove organic matter. The ash is dissolved in dilute nitric acid in the presence of strontium carrier and calcium and strontium precipitated as phosphate. The precipitate is dissolved in nitric acid and the acid concentration increased to precipitate the strontium as nitrate, After further nitric acid separations, barium carrier is added and a barium chromate separation made. The separated strontium is stored in the presence of yttrium carrier to allow 190 to grow in. The yttrium is milked off and counted. 
$\underline{\text { Special Reagents Required }}$

(i) Fuming nitric acid, 95-96 per cent $\mathrm{w} / \mathrm{w}$.

(if) Dilute acetic acid $6 \mathrm{M}$ 。

(i i i ) Ammonium acetate solution 3M.

(iv) Sodium chromate solution 1.5M.

(v) Oxalic acid solution, 8 per cent.

(vi) Strontium carrier solution, 5 . Sr per ml. standardized.

(vii) Yttrium carrier colution, 10 mo

(viii) Barium carrier solution, 10 mgm. Ba per ml.

(ix) Ferric iron carrier solution, 5 mgm. Fe per ml.

EXPERIMENTAL

\section{Procedure}

1. Weigh out 400 grm。dried milk into large silica dishes, Beat over a gas burner in fume hood until a carbonaceous mass is obtained。 Transfer to a muffle furnace at 700$800^{\circ} \mathrm{C}$ and heat until a white ash is obtained. Weigh and bottle the ash (Note (a)).

2, Weigh out $20 \mathrm{gm}$. of ash into $600 \mathrm{ml}$. beaker. Add $10 \mathrm{ml}$. strontium carrier, $200 \mathrm{ml}$. distilled water and $40 \mathrm{ml}$. $16 \mathrm{M}$ nitric acid, Wam and stir until a clear solution is obtained. Add $1 \mathrm{ml}$. syrupy (15M) phosphoric acid and neutralize with $17 \mathrm{M}$ ammonium hydroxide until ammonia is in excess. Transfer to two $200 \mathrm{ml}$. centrifuge bottles and centrifuge. Remove supernate and add $100 \mathrm{ml}$. distilled water to each bottle. Stir up the precipitate to obtain a slurry and centrifuge, Reject the washings.

3. Dissolve the precipitate by adding $20 \mathrm{ml}$ 。fuming nitric acid to each bottle and stirring, Combine the two solutions in a measuring cylinder and measure the volume, $2 \mathrm{~V} \mathrm{ml}$. Return half the solution, volume $v$, to each centrifuge bottle and add to each $2.5 \mathrm{~V}$ (70 ml.) fuming nitric acid. COOl in water with stirring for 30 minutes. Centrifuge and reject supernate,

\section{Procedure Notes}

(a) A portion of the milk ash is retained for calcium determinations, see Addendum 2 of method for animal bone ash. 
Procedure

$\underline{\text { Procedure Notes }}$

4. Dissolve the residues in 40.0 ml. distilled water. Add 90

ml. fuming nitric acid to each bottle

and cool with stirring for 30 minutes.

Centrifuge and reject supernate,

Transfer the residues to a 40 mi. centrifuge tube with $20-30 \mathrm{ml}$.

water.

5. Continue as from para. 3

of Procedure for the Determination

of Radiostrontium in animel bone

ash.

II.g. Determination of Radiostrontium in Vegetable Ash

Outline of Method

The vegetable ash is treated with dilute nitric acid in the presence of strontium carrier. The solution is evaporated nearly to dryness with perchloric acid and the silica filtered off. The calcium and strontium are precipitated as phosphate and the strontium removed from the mixed phosphates by a series of nitric acid separations. Barium carrier is added and a barium chromate separation made, followed by a ferric hydroxide scavenge to remove radium and its daughters.

The strontium is stored for at least 14 days in the presence of yttrium carrier, the yttrfum is then milked off and counted, The strontium is precipitated as carbonate and mounted for counting when further $\mathrm{Y} 90$ has grown in.

Special Reagents Required

(i) Fuming nitric acid, $95-96$ per cent $w / w$.

(1i) Dilute acetic acid, 6M.

(iii) Ammonium acetate solution 3M.

(Iv) Sodium chromate solution $1.5 \mathrm{M}$.

(v) Oxalic acid solution, 8 per cent.

(vi) Strontium carrier solution, 5 m. Sr per ml. standardized.

(vii) Yttrium carrier solution, $10 \mathrm{mgm}$ Y per ml. standardized.

(viii) Barium carrier solution, $10 \mathrm{mgm}$. Bs per ml.

(ix) Ferric iron carrier solution, 5 mo per m. 
1. Weigh $10 \mathrm{gm}$. of sample into a shallow beaker (about 4 inches high by 6 inches diameter). Add $50 \mathrm{ml}$. distilled water and $10 \mathrm{ml}$. strontium carrier solution, Dissolve the sample, as completely as possible, by the addition of $50 \mathrm{ml}$. $16 \mathrm{M}$ nitric acid. Then add $50 \mathrm{ml}$. 60 per cent perchloric acid and evaporate under an infra red lamp nearly to dryness.

2, Leach the residue with 80 $100 \mathrm{ml}$. distilled water and filter through a No. 54 Whatman filter paper on a Buchner funnel, washing the precipitate with an equal quantity of water. Transfer the filtrate to a $600 \mathrm{ml}$. beaker and adjust the volume to 250-300 $\mathrm{ml}$. Add $5 \mathrm{ml}$. syrupy (I5M) phosphoric acid followed by the addition of $17 \mathrm{M}$ ammonium hydroxide whilst stirring until an excess of ammonia is detected,

3. Transfer the contents of the beaker to a $200 \mathrm{ml}$. centrifuge bottle, centrifuging and rejecting the supernate, until all the precipitate has been collected in the bottle, Wash the precipitate by stirring with 100 ml. distilled water, centrifuge and reject the supernate,

4. Dissolve the precipitate by the addition of $20.0 \mathrm{ml}$ 。 fuming nitric acid and transfer to a measuring cylinder. Mote the volume $V$ and return the solution to the centrifuge bottle. Add 2.5V (70 ml.) fuming nitric acid and cool in running water for 30 minutes, stirring occasionally.

5. Centrifuge and reject the supernate. Dissolve the residue in $40.0 \mathrm{ml}$. distilled water, add 90.0 ml. fuming nitric acid and cool with 
stirring for 30 minutes. Centrifuge and reject the supernate. Transfer the residue to $40 \mathrm{ml}$. centrifuge tube with 20-30 ml. water.

6. Continue as described in para. 3 of the Procedure for the Determination of Radiostrontium in Bone Ash.

$\underline{\text { Addenda }}$

Deter of calcium t of vegetab] is

Weigh about $1 \mathrm{gm}$ of the ash accurately into a $3-1 / 2$ inch platinum dish. Add $20 \mathrm{ml}$. distilled water and then cautiously add $20 \mathrm{ml}$. 60 per cent perchloric acid and about $20 \mathrm{ml}$. 40 per cent hydrofluoric acid. Warm on hot plate in fume cupboard and evaporate until dense white fumes of perchloric acid appear. Cool, add a further $20 \mathrm{ml}$. hydrofluoric acid and evaporate as before. Continue the evaporation almost to dryness and dissolve the residue in 40-50 $\mathrm{ml}$. water. Transfer to $400 \mathrm{ml}$. beaker and add $40 \mathrm{ml}$. oxalic acid. Wam to about $80^{\circ} \mathrm{C}$ and neutralize with $4 \mathrm{M}$ ammonium hydroxide solution to a $\mathrm{pH}$ value of 4.0. Stand in warm for 3-4 hours and filter into a tared sintered glass crucible, porosity 4 . Wash four times with distilled water and methanol. Dry in oven at $110-115^{\circ} \mathrm{C}$ and reweigh. Calculate the calcium content of the vegetable ash, the calcium being weighed as calcium oxalate monohydrate, conversion factor 0.2743 . 


\section{II.h. Alternate Procedure for Vegetable Ash}

Outline of Method

Vegetable ash may be brought into solution more readlly and with better recovery of strontium by fusing the ash with four times its weight of sodium carbonate. Fusion is continued until the melt Is clear, after which the crucible is allowed to cool. The residue is treated with water and dissolved in perchloric acid. The solution may then follow the procedure outlined in II.g.

This method is taken from Report NYO-4700 and is to be recommended in place of that outlined in II.g.,

\section{II.1. Determination of Radiostrontium in Urine}

Outline of Method

A urine sample should be wet ashed with an equal volume of nitric acid and with further additions if necessary to produce a white ash. The urine ash should be treated as vegetation ash in Method II.g., beginning with the phosphate precipitation step.

II.j. De.termi.nation of Radias.trontium in Feces Ash

Quttine of Methog

Feces ash should De fused with sodium carbonate and treated as vegetation ash in Method II.h. 